Check for updates

Cite this: RSC Adv., 2019, 9, 29154

Received 31st July 2019

Accepted 29th August 2019

DOI: $10.1039 / c 9 r a 05954 g$

rsc.li/rsc-advances

\section{Printed electronics based on inorganic conductive nanomaterials and their applications in intelligent food packaging}

\author{
Yu Liao, ${ }^{\text {ab }}$ Rui Zhang and Jun Qian (D)*a
}

\begin{abstract}
The diverse demands of consumers for packaging functions and increasingly complex product circulation systems have spurred the development of intelligent food packaging (IFP). Besides the basic functions of traditional food packaging, which include the protection of food, sales promotion and convenient transportation, the developing area of IFP can detect the condition of food (ambient temperature, humidity, corruption degree, etc.) in one whole product cycle, and record and feedback information regarding the quality of the packaged food to form a complete product monitoring system. Recently, cutting-edge printed electronics (PE) technology has opened new opportunities for the realization and expansion of IFP functions. Here we introduce some new printed sensors and radio frequency identification (RFID) tags, which are used to form an IFP system. Since conductive ink is the cornerstone of $\mathrm{PE}$, in this paper, the synthesis and properties of inorganic conductive nanomaterials are also reviewed. The formulation of conductive ink, sintering methods and the flexible substrates used in PE are also discussed. Focusing on the state-of-the-art application of PE in the field of IFP, the purpose of this article is to provide a review of IFP that integrates emerging PE technology with prospective nextgeneration IFP systems to sense, detect, and record feedback information on products in the supply chain environment.
\end{abstract}

\section{Introduction}

Detecting the freshness and safety of food has become a significant challenge in the global supply chain and with the demand for minimally processed food products. Therefore, there is a continued demand for new analytical technologies that can detect the ambient environment and freshness of packaged food in a more time-effective manner. The continuing evolution of large-area radio frequency identification (RFID) and printed sensor production is spurred by the development of printed electronics (PE). Once we reduce the cost of such packaging, RFID and printed sensors can be applied to food packaging. The synergistic integration of intelligent food packaging (IFP) with PE technologies, which has transitioned from science fiction to an area of focus, satisfies the need for the protection of food from environmental pollution, and plays an active role in the quality and safety of food. It prolongs the shelf life using functions that traditional packaging cannot realize, for example judging the freshness of food, the authenticity of drugs, the environmental factors (temperature, humidity, light etc.) in circulation, and so on. ${ }^{1-4}$ Recent trends in IFP include: (i)

${ }^{a}$ School of Printing and Packaging, Wuhan University, Luojia Hill, Wuhan, 430072, China.E-mail:whuqianjun@163.com

${ }^{b}$ Chemical \& Environmental Engineering, School of Engineering \& Applied Science, Yale University, 17 Hillhouse Avenue, New Haven, CT 06511, USA theoretical research on internal environmental factors of packaging that impair the shelf life of food, such as gas composition, temperature, microorganisms, etc.; (ii) materials or strategies that are optimized to detect changes in products and to provide effective information to the packaging users (consumer or production decision-makers); and (iii) challenges such as cost minimization that still lie ahead. This review is an effort to familiarize readers with the great breakthrough of IFP in protecting food quality and safety in the dynamic and diverse

The burgeoning PE technology provides a possibility for the realization of IFP. As an interdisciplinary technology between printing and electronics, PE uses a printing process, such as inkjet printing, screen printing, nanoimprinting or soft lithography, etc. to prepare electronic circuits on a flexible substrate..$^{5-11}$ To date, low-cost has been the main driving force in the development of the electronics. For a cost-effective and high-volume process, a printing method like the roll-to-roll (R2R) manufacturing platform has been used to fabricate PE five decades, microelectronics has dominated electronic technology. Table 1 shows the differences between PE and microelectronics. The complexity and huge investment in hard electronic devices made by traditional microelectronic technology is incompatible with the low-cost, high throughput production which is necessary for practical applications in circulation environment. that is becoming ultra-light and ultra-thin., ${ }^{8,12}$ During the past 
Table 1 A comparison between PE and microelectronics

\begin{tabular}{lll}
\hline & PE & Microelectronics \\
\hline Advantages & $\begin{array}{l}\text { Light, can be flexible when it prints on flexible } \\
\text { substrates, easily distributed, greatly reduced } \\
\text { thickness with invariant integration level, low } \\
\text { cost } \\
\text { High requirements for mechanical properties } \\
\text { and encapsulation } \\
\text { Print, R2R }\end{array}$ & $\begin{array}{l}\text { No onerous requirements of mechanical } \\
\text { properties, fast running }\end{array}$ \\
Misadvantages & Flexible substrates (plastic, paper, etc.) & Heavy, hard and dispersed \\
Substrates & & $\begin{array}{l}\text { No mass production, high cost, low efficiency, } \\
\text { environmental pollution } \\
\text { Rigid substrates (silicon substrate, glass } \\
\text { substrate) }\end{array}$
\end{tabular}

packaging. Conversely, PE can be applied. For example, RFID has been widely used for electronic labeling in packaging.

Conductive ink is the foundation stone for the fabrication of PE and offers good performance as shown in Fig. 1. In this figure, a complete process is illustrated, from the preparation of conductive ink, to the printing process and applications in IFP. The preparation of high-quality conductive ink is a recent research hotspot. Nano-conductive ink is a functional ink developed rapidly with modern science and technology. It is a kind of multi-component dispersion in solvent, containing mainly resins used as a binder to adhere to the substrates, oils as the carrier or medium of the nanomaterial additives to control the rheological properties of the ink, and nanomaterials as the conductive fillers. ${ }^{\mathbf{1 2 - 1 6}}$ In this review, the synthesis and stabilization of two kinds of inorganic conductive nanomaterials (metal nanoparticles (NPs) and carbon nanomaterials), and sintering processes are briefly introduced.

The review will focus on the latest progress in the utilization of PE for the fabrication of various IFP. The main focus of the present study is the utilization of PE to realize new IFP with diversified functions. We will explore the issues around expanding the diversity of functions while reducing the additional cost of packaging. In brief, parallel activities of laboratory research (developing new applications of PE in IFP) and commercialization (reducing cost and increasing production efficiency) are needed to promote the development of new functions and the commercialization of IFP. We hope that PE can be better integrated into IFP to broaden its application prospects and increase market capacity.

\section{Printable conductive nanomaterials}

\subsection{Conductive ink: requirements and conduction mechanism}

The formulations and preparation methods of conductive inks are crucial if they are to demonstrate good printability, with the appropriate viscosity and surface tension as well as adhesion to specified substrates. ${ }^{\mathbf{1 3 , 1 7 , 1 8}}$ However, several key characteristics, such as the viscosity and ink particle size, should be adjustable to fit different printing methods. Table 2 (ref. 19) shows a comparison of different printing methods (piezoelectric inkjet printing, aerosol jet printing, screen printing, gravure printing, flexographic printing, gravure offset printing and letterset printing) with respect to several technical parameters (optimum range of viscosity, single printing ink film thickness, pattern resolution and printing speed). It is desirable to prepare nanosheet (NS) and nanoparticle (NP)-based conductive inks with well-enhanced electrical conductivity. There are many factors which can affect the conducting performance of ink, such as its composition and the post-processing methods used. Moreover, the mechanisms, which mainly include percolation, the tunnel effect and the field emission effect, can change with the different ink types and the concentration of conducting fillers. Fig. 2 illustrates the conducting mechanism of conductive ink from the colloid state to solidified film printing on the substrate. The conductive ink remains insulating unless the solvent volatilizes and promotes stable binding between the conductive NPs and the matrix (this process is often denoted as the drying of the ink).

After the drying of the conductive ink on the substrate, the conductive NPs mainly exist in three states: a continuous contact state forming a current path termed as percolation; a partly continuous contact state, in which thermal vibration causes electrons to drift through the gaps between the NPs and create an electronic pathway (namely, the tunnel effect); and a completely discontinuous state in which the particles cannot form an electronic pathway because of large gaps between the NPs. ${ }^{19-21}$

\subsection{Metal NPs}

2.2.1 Synthesis of metal NPs. A large number of conductive NPs are a basic prerequisite for conductive ink. Metals with high conductivity are the best candidates for conductive materials. Silver $(\mathrm{Ag})\left(\rho=1.586 \Omega \mathrm{m}, 20^{\circ} \mathrm{C}\right)$, copper $(\mathrm{Cu})(\rho=1.678 \Omega$ $\left.\mathrm{m}, 20{ }^{\circ} \mathrm{C}\right)$, gold (Au) $\left(\rho=2.40 \Omega \mathrm{m}, 20{ }^{\circ} \mathrm{C}\right)$, aluminum (Al) $(\rho=$ $\left.2.46548 \Omega \mathrm{m}, 20{ }^{\circ} \mathrm{C}\right)$ and nickel $(\mathrm{Ni})\left(\rho=6.84 \Omega \mathrm{m}, 20{ }^{\circ} \mathrm{C}\right)$ are mostly used as conductive nanofillers, among which Ag is the most promising both in the laboratory and in practical industrial applications. ${ }^{22-24}$ Currently, metal NPs can mainly be synthesized by two means: top-down methods and bottom-up methods.

Top-down methods use physical methods (mechanical grinding, laser ablation, physical vapor deposition, etc.) to break 


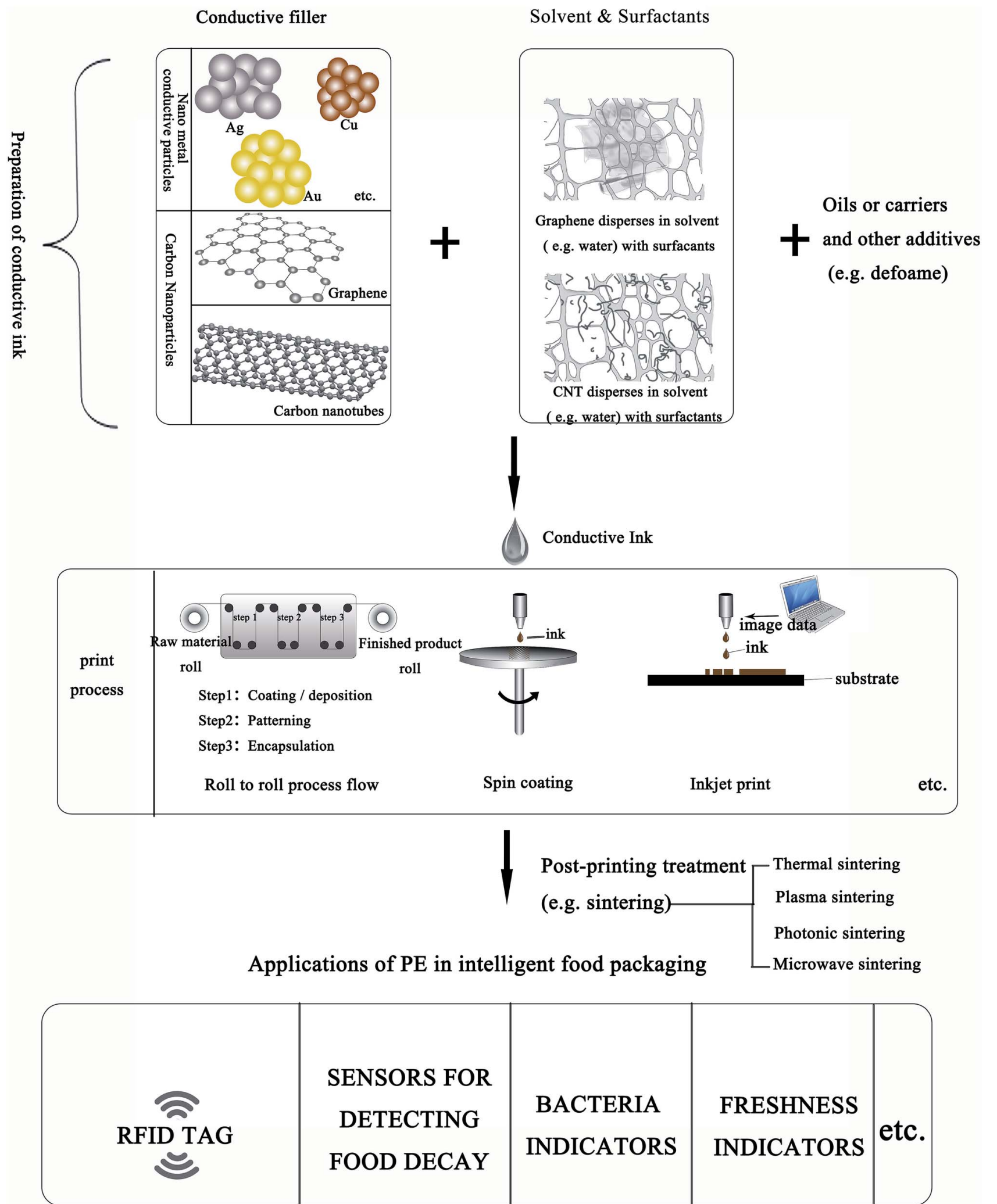

Fig. 1 Summary of the preparation of conductive ink based on inorganic conductive nanomaterials, and the applications of PE in IFP.

bulk metal into nanoscale particles. The most common method among several top-down methods is physical vapor deposition. The metal vapor is prepared by plasma excitation or thermal heating of the bulk metal, by which the metal wires or metal powders vaporize and condense rapidly through a stream of inert gas like $\mathrm{N}_{2}$ or $\mathrm{Ar}$ in the solution. Wang et al. ${ }^{25}$ have 
Table 2 Comparison of different printing technologies

\begin{tabular}{lllll}
\hline Printing technology & $\begin{array}{l}\text { Optimum range of } \\
\text { viscosity/cP }\end{array}$ & $\begin{array}{l}\text { Single printing } \\
\text { ink film thickness } / \mu \mathrm{m}\end{array}$ & Pattern resolution/ $\mu \mathrm{m}$ & ${\text { Printing speed } /\left(\mathrm{m}^{2} \mathrm{~s}^{-1}\right)}^{-1}$ \\
\hline Piezoelectric inkjet printing & $5-20$ & $0.05-1$ & $>20$ & $\leq 0.5$ \\
Aerosol jet printing & $1-1000$ & $0.1-5$ & $>8$ & $\leq 0.01$ \\
Screen printing & $500-10000$ & $\leq 100$ & $>50$ & $0.1-10$ \\
Gravure printing & $50-500$ & $0.8-8$ & $>20$ & $3-60$ \\
Flexographic printing & $50-200$ & $0.8-2.5$ & $>50$ & $3-30$ \\
Gravure offset printing & $>50$ & $0.5-6$ & $>20$ & $0-30$ \\
Letterset printing & $50000-150000$ & $0.5-1.5$ & $>50$ & $0.5-2$
\end{tabular}

reported the preparation of Ag NPs with sizes between $2 \mathrm{~nm}$ and $6 \mathrm{~nm}$ by plasma vapor deposition. However, the need for sophisticated equipment and severe operating conditions hamper the commercialization of this high-energyconsumption method.

Conversely, bottom-up routes decompose the precursor in solution or reduce it in the presence of a reducing agent to form a metal ionic liquid which will form unique nanostructures by self-assembly. ${ }^{26}$ Fig. 3 shows the synthetic process for metal NPs using a chemical reduction method. The bottom-up routes make it possible to prepare a large number of different sizes of metal NPs by adjusting parameters such as the types and dosages of the reducing agent, $\mathrm{pH}$ and temperature, to affect the growth of the crystals and finally control the sizes, shapes and distribution properties of the products. The most commonly used reductants include borohydride, ${ }^{27}$ hydrazine,$^{28}$ ascorbic acid $^{29}$ and citrate, ${ }^{30}$ etc. Tippabattini Jayaramudu et $a{ }^{31}$ have synthesized nano-Ag particles with a uniform average size between 10 and $12 \mathrm{~nm}$ using silver nitrate as the precursor and polyethylene glycol as the reducing agent. The advantages of this method which include the production of uniform microstructures and low energy consumption have impelled researchers to put more effort into finding the optimal synthetic parameters. Compared with physical methods, the bottom-up routes are more suitable for the commercial application of IFP.

2.2.2 Stabilization of dispersions. Brownian motion can often cause metal NPs that are dispersed in a solvent to cohere and precipitate during collisions. It is a major challenge in the field of PE to stabilize the metal NPs in the solvent and to prolong the shelf life of the conductive ink. Scientifically, there are two main stabilization methods used to solve this problem, namely electrostatic stabilization and steric stabilization..$^{32-34}$ The most effective way is to add stabilizers into the metal NP

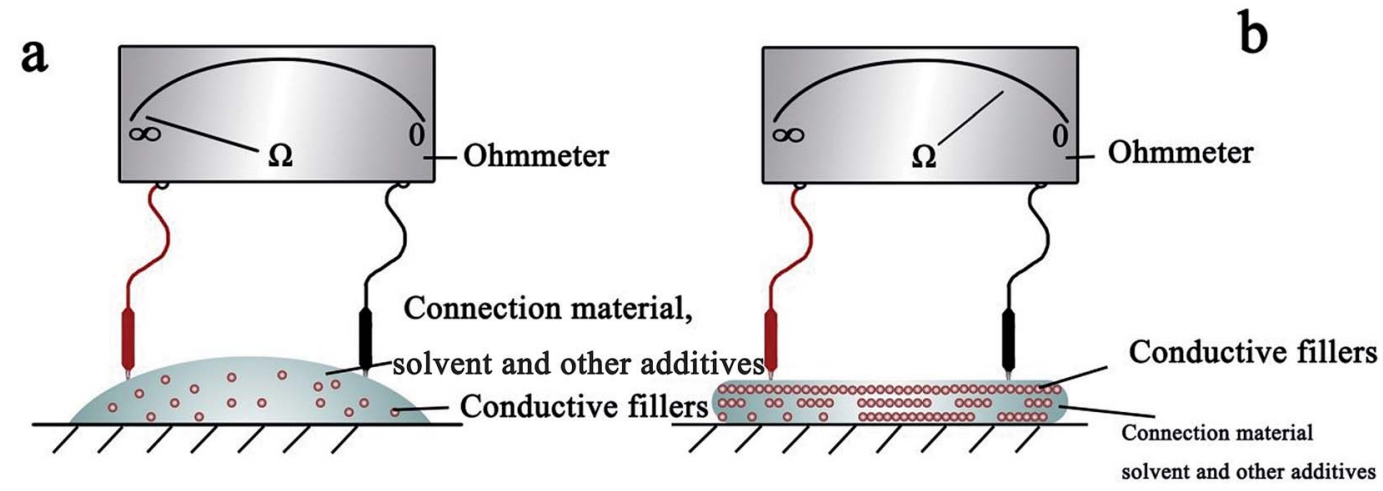

C

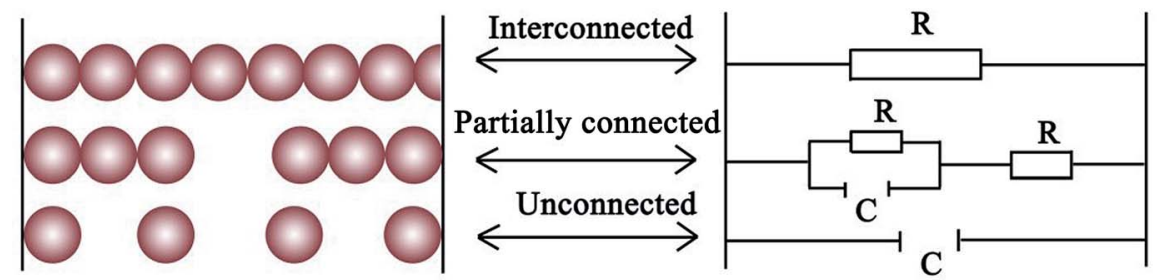

Fig. 2 A schematic diagram of the conduction mechanisms of conductive ink: (a) less conductive particles, where the residual solvent barrier between conductive particles and charge transfer resistance are very large, (b) conductive particles in close contact, where the resistance is lower, and (c) the three connection states of the conductive ink. 


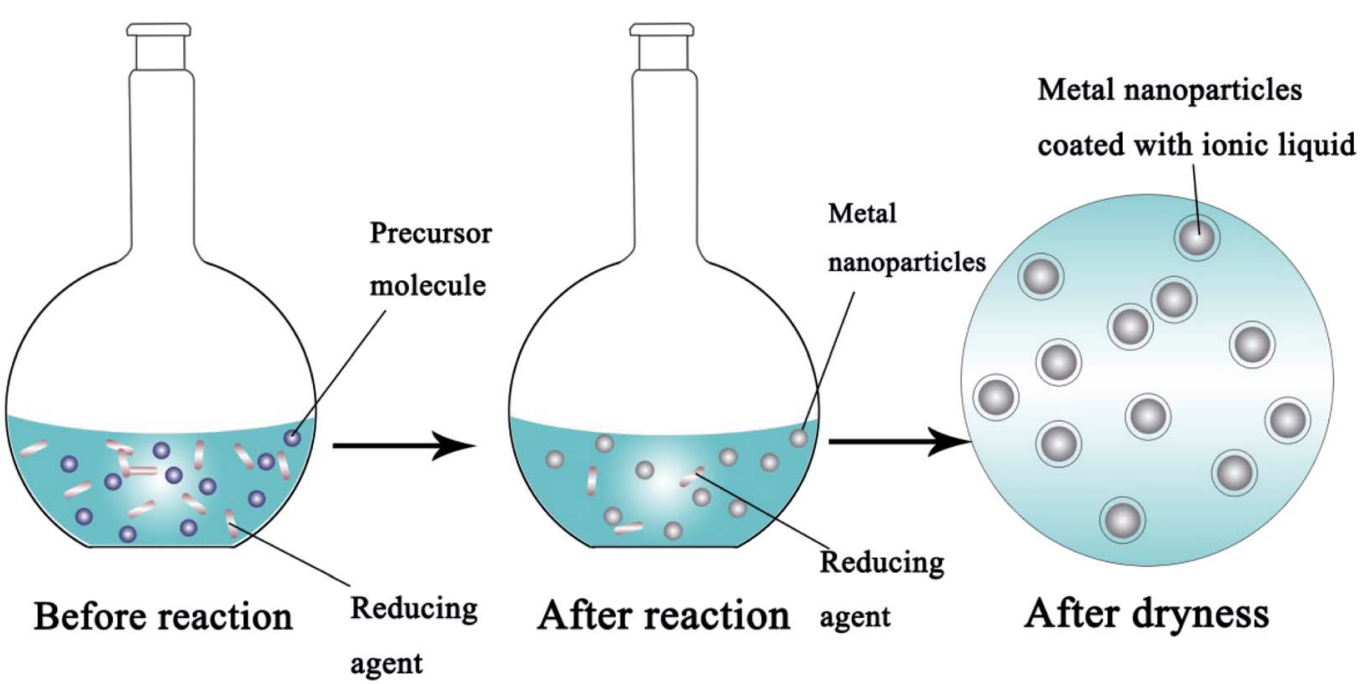

Fig. 3 Schematic diagram of the "bottom up" route of metal NP synthesis by a chemical reduction method.

preparation process while the embryo of metal is still growing. The addition into the solution of ionic-free amphiphilic polymers containing both a hydrophobic portion and a hydrophilic one can form stable conductive inks. Moreover, it enables a higher concentration of metal NPs to disperse effectively in the solution. Polyvinylpyrrolidone (PVP), ${ }^{35}$ sodium carboxymethyl cellulose, ${ }^{36}$ naphthalene sulfonic acid, formaldehyde condensate, polyacrylate etc. are the most commonly reported stabilizers. ${ }^{37}$ For example, Mihwa Seo et al. ${ }^{38}$ have studied how the types of organic stabilizer (in neodecanoic acid-stabilized Ag NPs (Ag-ND), hexyl amine-stabilized Ag particles (Ag-HA) and polyvinylpyrrolidone-stabilized Ag particles (Ag-PVP)) influence the ink's resistivity. They concluded that Ag-ND has the lowest resistivity $(3.5 \mu \Omega \mathrm{cm})$ compared to $15 \mu \Omega \mathrm{cm}$ for Ag-PVP, and 4.0 and $5.7 \mu \Omega \mathrm{cm}$ for Ag-HA1, and Ag-HA2 (larger sized NPs). Fig. 4 shows the SEM images of the four nano $\mathrm{Ag}$ films made using different stabilizers at different sintering temperatures.

2.2.3 Stabilization against oxidation. As a low-priced metal, $\mathrm{Cu}$ is an alternative to the noble metals such as $\mathrm{Ag}$ and $\mathrm{Au}$ which have low-melting-temperatures together with high conductivity $\left(10^{-3}\right.$ to $\left.10^{-2} \Omega \mathrm{cm}\right)$. However, $\mathrm{Cu}$ is prone to oxidation which causes a deterioration in resistivity and a higher sintering temperature. ${ }^{22}$ Accordingly, concerted efforts are being made to search for effective methods to stabilize $\mathrm{Cu}$ against oxidation. One of the most common ways is to form a protective coat around $\mathrm{Cu}$ NPs in solution to protect them from being oxidized; another method is to add antioxidants such as ascorbic acid. Cheng et al. ${ }^{39}$ presented a method of synthesizing Cu NPs with an average size of $140 \mathrm{~nm}$ which remained in a stable state for 3 months without oxidation at room temperature. They used PVP as a capping agent and ascorbic acid as an antioxidant. Nevertheless, the aforementioned approaches can only retard the oxidation of metal NPs. More effective ways to prevent from oxidation need to be developed. Recently, some research groups have synthesized a kind of antioxidative $\mathrm{Cu}$ NP with a dense shell. Yim et al. ${ }^{40}$ fabricated hybrid copper-silver-graphene (CSG) nanoplatelet conductive inks which showed the desired oxidation resistance even at high temperatures. This CSG film displayed an electrical resistance of a few ohms at $190^{\circ} \mathrm{C}$. PajorŚwierzy et al. ${ }^{41}$ recently presented a kind of conductive ink based on $\mathrm{Cu}$ and $\mathrm{Ag}$ core-shell particles. It was air stable with a lowest resistivity of $6.9 \pm 0.7 \mu \Omega \mathrm{cm}$ that corresponds to $25 \%$ of the conductivity of bulk $\mathrm{Cu}$.

2.2.4 Sintering and resistivity. A sintering process is often needed to obtain high electrical conductivity that parallels that of the bulk metal. Thermal sintering with temperatures ranging from $150{ }^{\circ} \mathrm{C}$ to $300{ }^{\circ} \mathrm{C}$ is a widely used method. Fig. 4 shows the effects of different sintering temperatures on the microstructures of NPs. The result shows that the density increases rapidly with rising temperature from $100-220{ }^{\circ} \mathrm{C}$. Table 3 shows the sintering temperature and the conductivity of various metallic nano-conductive inks for PE. Photonic sintering ${ }^{42,43}$ (which is a high-temperature thermal processing of thin films using a broad-spectrum pulse of light from a flash lamp), plasma sintering $^{44}$ (which needs sophisticated equipment and compatibility with plastic substrates) and microwave sintering ${ }^{45}$ (which has a small penetration depth) are also commonly reported methods. However, the biggest challenge arises where patterns need to be printed on flexible substrates such as plastic film that cannot withstand severe conditions. Hirotaka Koga et al. ${ }^{46}$ developed a rapid low-temperature sintering method to fabricate $\mathrm{Ag}$ conductive ink for PE. The as-printed films were sintered at $75^{\circ} \mathrm{C}$ and yielded high conductivities of $2.74 \times 10^{6} \mathrm{~S}$ $\mathrm{m}^{-1}$. In addition, the optimal sintering temperature strongly depends on the ligands. For example, the optimal sintering temperatures for $\mathrm{Ag}$ NPs are $140{ }^{\circ} \mathrm{C}$ (ref. 47) and $450 \mathrm{~K}$ (ref. 48) respectively for PVP and poly(diallyldimethylammonium chloride) ligands. Anni ${ }^{49}$ used xylene as the dispersant to prepare $\mathrm{Au}$ NP conductive ink with the best sintering temperature of $180^{\circ} \mathrm{C}$, and $\mathrm{Yun}^{50}$ prepared $\mathrm{Ag}$ inks with an optimal sintering temperature of $70{ }^{\circ} \mathrm{C}$ using a hydroxyethyl cellulose adhesive agent. Ligands can make conductive NPs more uniform and stable in the dispersion system, but the presence of ligands prevents the transfer of charge between conductive particles 


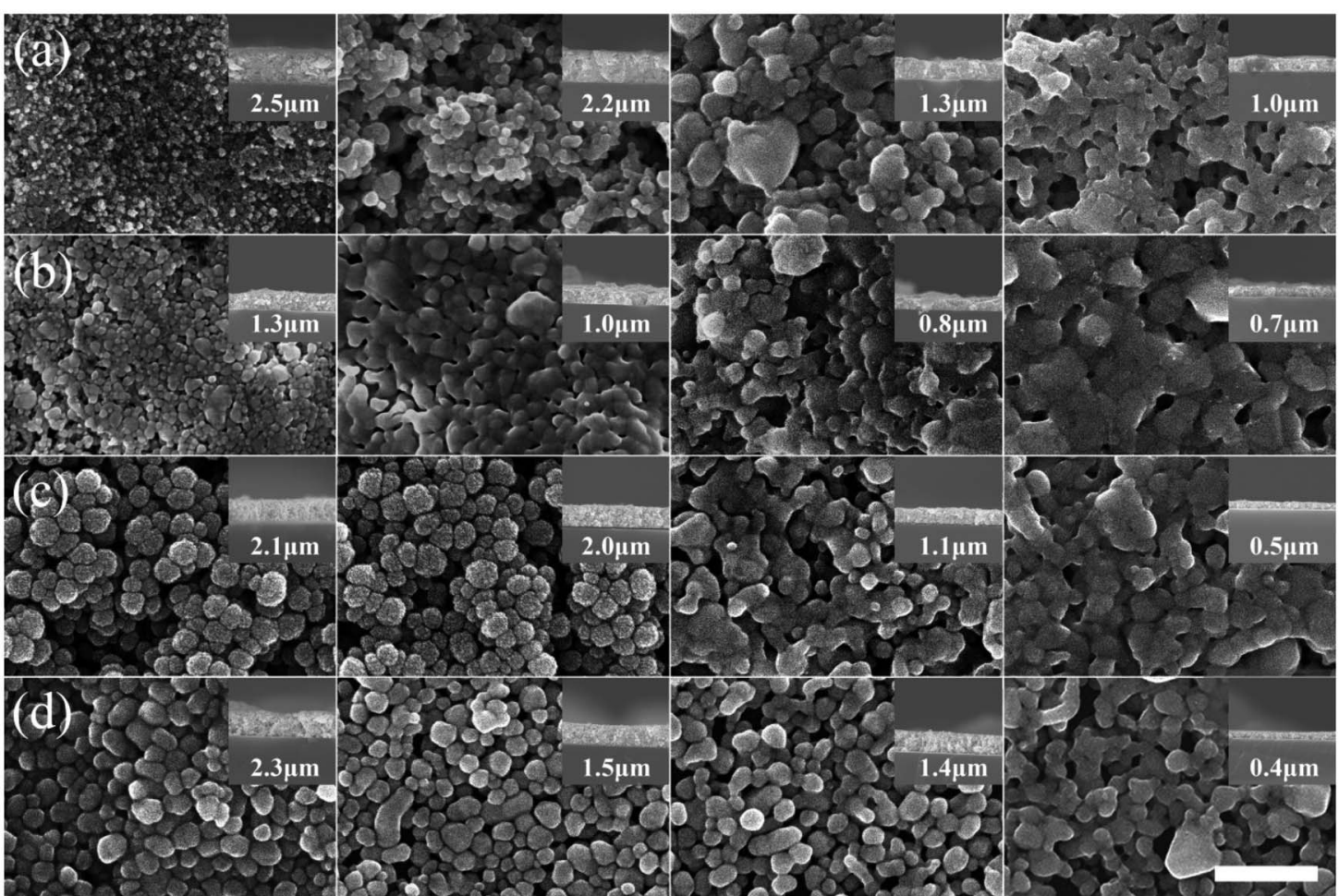

Fig. 4 SEM images (top and side views) of nano Ag films: (a) Ag-ND, (b) Ag-HA1, (c) Ag-HA2, and (d) Ag-PVP sintered at various temperatures (left to right: $100^{\circ} \mathrm{C}, 140^{\circ} \mathrm{C}, 180^{\circ} \mathrm{C}$, and $220^{\circ} \mathrm{C}$ ); scale bar $=500 \mathrm{~nm}$ [reprinted with permission from ref. 38, M. Seo, J. S. Kim, J. G. Lee, S. B. Kim and S. M. Koo, The effect of silver particle size and organic stabilizers on the conductivity of silver particulate films in thermal sintering processes, Thin Solid Films, 2016, 616, 366-374. Copyright@ Elsevier]

and increases the resistance of printed circuits, so different ligands have different sintering temperatures.

\subsection{Carbon NSs and NPs}

Because of their excellent chemical, electrical, mechanical, and optical properties as well as their abundance, graphene and carbon nanotubes (CNTs) are emerging as promising candidates for metal NPs. ${ }^{6,9,12,13,18,55-57}$ Since 2004, more and more of the literature has focused on the preparation of graphene and CNTs. Where and how we can apply graphene in new fields and for new functions has become a wide-spread challenge.

2.3.1 Graphene. Graphene is 2D structured material with a single atomic layer of $\mathrm{sp}^{2}$ hybridized carbon atoms. ${ }^{58-61}$ There are several methods used to synthesize graphene: mechanical

Table 3 Sintering temperatures and conductivities of various metal NP inks for PE

\begin{tabular}{llll}
$\begin{array}{l}\text { Conductive } \\
\text { particles }\end{array}$ & Sintering temperature & Conductivity & Ref \\
\hline $\mathrm{Ag}$ NPs & $300^{\circ} \mathrm{C}$ & $3.2 \mu \Omega \mathrm{cm}$ & 47 \\
$\mathrm{Cu}$ ion & $90{ }^{\circ} \mathrm{C}$ & $2.3 \times 10^{-6} \Omega \mathrm{cm}$ & 51 \\
$\mathrm{Cu} \mathrm{NPs}$ & $150{ }^{\circ} \mathrm{C}$ & $3.23 \mu \Omega \mathrm{cm}$ & 44 \\
$\mathrm{Au} \mathrm{NPs}$ & $180{ }^{\circ} \mathrm{C}$ & $1.6 \times 10^{-7} \Omega \mathrm{m}$ & 49 \\
$\mathrm{Zn} \mathrm{NPs}$ & $25{ }^{\circ} \mathrm{C}$ & $3 \times 10^{5} \mathrm{~S} \mathrm{~m}^{-1}$ & 52 \\
$\mathrm{Ni} \mathrm{NPs}$ & $150{ }^{\circ} \mathrm{C}$ & $76.34 \mu \Omega \mathrm{cm}$ & 53 \\
$\mathrm{Cu} / \mathrm{Ag} \mathrm{NPs}$ & $100{ }^{\circ} \mathrm{C}$ & $5.12 \mu \Omega \mathrm{cm}$ & 54
\end{tabular}

exfoliation, liquid exfoliation (LE), microfluidization, solid exfoliation, oxidation-exfoliation-reduction and chemical vapor deposition (CVD), etc. ${ }^{22,62}$

2.3.2 Synthesis of graphene. Initially, graphene was prepared by mechanical exfoliation from graphite. ${ }^{\mathbf{9 6 3 - 6 5}}$ Due to the weak interlayer attractions in graphite, graphene can be easily exfoliated with simple equipment., ${ }^{\mathbf{6} 66}$ However there are several disadvantages of this method: (i) the degree of exfoliation must be controlled carefully; and (ii) it has a low production efficiency which makes it unsuitable for large scale commercial manufacture.

Oxidation-exfoliation-reduction is the most commonly reported method used to prepare graphene. As shown in Fig. 5, firstly, strong oxidizers ${ }^{65}$ are used, such as fuming nitric acid, ${ }^{67,68}$ potassium perchlorate ${ }^{69}$ or potassium permanganate ${ }^{70}$ to oxidize the graphite. Oxygen-containing groups such as carboxyl and hydroxyl are formed, causing an increase in the interlayer distance of graphite from $3.35 \AA$ to $7-10 \AA{ }^{71-74}$ The asprepared graphene oxide (GO) can then easily be exfoliated by ultrasonic treatment, and finally graphene can be prepared by reduction. For example, Hong et al. ${ }^{74}$ prepared graphene ink with the Hummers' method using hydrazine as a reducing agent under anoxic conditions. Then, they mixed the asprepared graphene with cellulose acetate, acetone, $n$-butyl pyridinium hexafluorophosphate and cyclohexanone, and sonicated for a given amount of time. They fabricated electrodes for $\mathrm{Cd}^{2+}$ and $\mathrm{Pd}^{2+}$ determination using the as-prepared graphene 


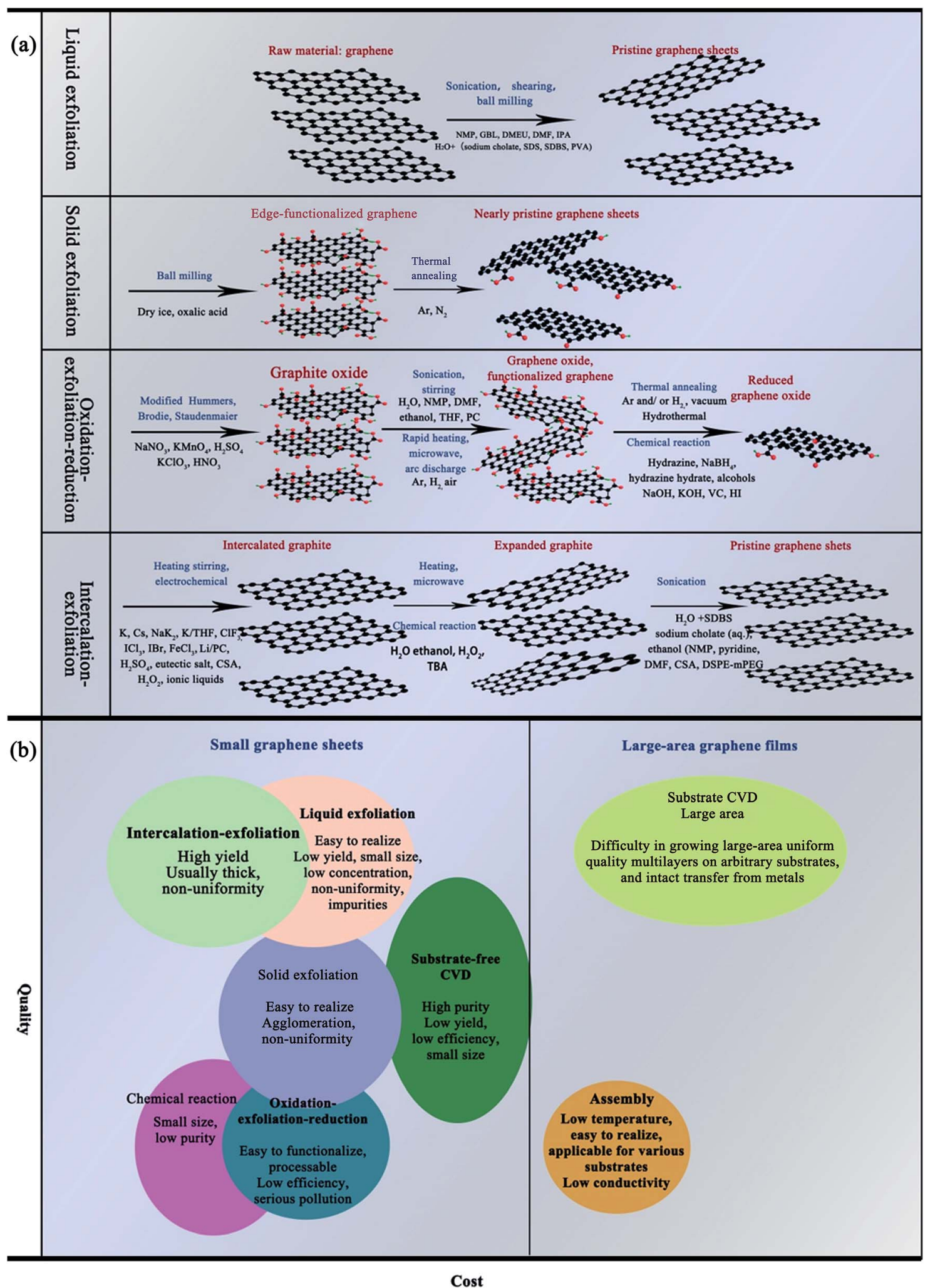

Fig. 5 (a) Schematic diagram of the synthesis of graphene from graphite. (b) Comparison of the quality and cost of graphene products manufactured by different methods [reprinted with permission from ref. 75, W. Ren and H. M. Cheng, The global growth of graphene, Nat Nanotechnol, 2014, 9, 726-730. Copyright@ Springer Nature]. 
ink by screen printing and obtained an excellent transfer resistance $(430 \Omega$ ). Fig. 5 shows several methods used for synthesizing graphene from graphite, and compares the quality and cost of the graphene products manufactured by the different methods.

LE is another method used to produce graphene. The process involves ultrasonic treatment of the graphite dispersed in solvent followed by centrifugation to obtain graphene. ${ }^{76}$ Arhin et al. ${ }^{77}$ prepared inkjet-printed graphene ink using graphene produced by ultrasonic-assisted liquid phase exfoliation. They ultrasonicated $100 \mathrm{mg}$ graphite flakes with $1.5 \mathrm{mg}$ PVP in $10 \mathrm{~mL}$ isopropanol for $12 \mathrm{~h}$ at $15{ }^{\circ} \mathrm{C}$ and then centrifuged at $4000 \mathrm{rpm}$ for $1 \mathrm{~h}$. As shown in Fig. 6, graphene was obtained with an average flake thickness of $5.9 \pm 0.2 \mathrm{~nm}$ and with $56 \%$ of flakes being $4 \mathrm{~nm}$ thick. Recently, microfluidization of graphite (which is similar to LE) has been developed by stripping graphite in aqueous solutions with high shear rates. This is a simple and scalable production route for conductive inks for large-area printing in flexible electronics.

Besides, CVD is a method commonly used in industry to produce high-quality graphene sheets with large areas. Osikoya et al. fabricated a CVD graphene sheet grown from acetylene as the carbon source, with a large available surface area, while the sheet resistance was as low as $125 \Omega \mathrm{sq}^{-1} \cdot{ }^{78-80}$ However, the biggest challenges for this technique are the high cost and complex processes involved.
2.3.3 CNTs. CNTs as another nanomaterial have been utilized in fabricating conductive inks because of their extraordinary electrical, optical, and mechanical properties. ${ }^{\mathbf{8 1 - 8 3}}$ He and Tjong ${ }^{8}$ prepared a kind of conductive ink containing 0.1 wt $\%$ multi-walled CNTs (MWNTs) and $0.2 \mathrm{wt} \%$ GO. The conductive ink was utilized in the scalable production of conductive films with a sheet resistance of $380 \Omega \mathrm{sq}^{-1}$ and $85 \%$ transparency. Shin et $a .^{83}$ developed a kind of CNT-based conductive ink that could be utilized in the fabrication of $2 \mathrm{D}$ flexible electronics. They used DNA as the surfactant to disperse the CNTs in methacryloyl and hyaluronic acid to fabricate ecofriendly conductive ink. Flexible electronics using this kind of ink displayed a $25 \%$ variation in the measured resistance even with a $180^{\circ}$ folding angle. Liao et al. ${ }^{13}$ reported a highly conductive carbon-based aqueous ink for electroluminescent devices, printed capacitive sensors and flexible wearable electronics.

2.3.4 Stabilization of dispersed carbon NS and NP-based conductive inks. Although promising for application, the poor dispersibility of graphene and CNTs is a stumbling block in the field of conductive inks and hinders the realization of high conductivities. Theoretically, graphene and CNTs are apt to aggregate and precipitate irreversibly in solvent due to van der Waals forces and $\pi-\pi$ stacking between the graphene lamellae. The methods used to promote the dispersion of graphene can
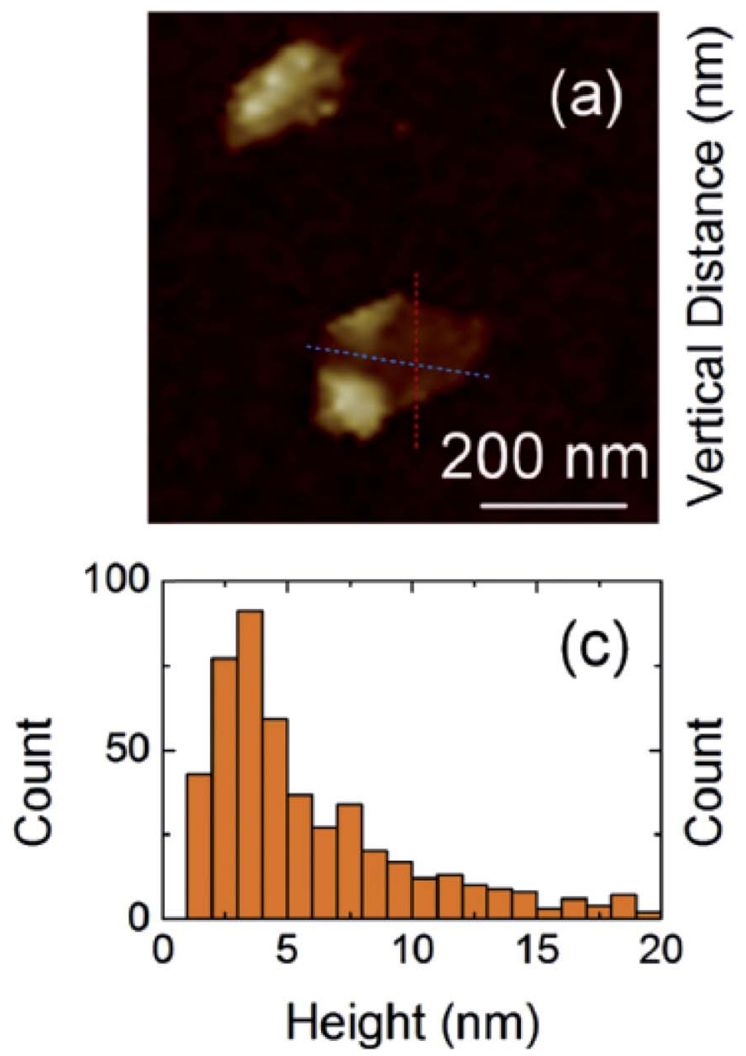
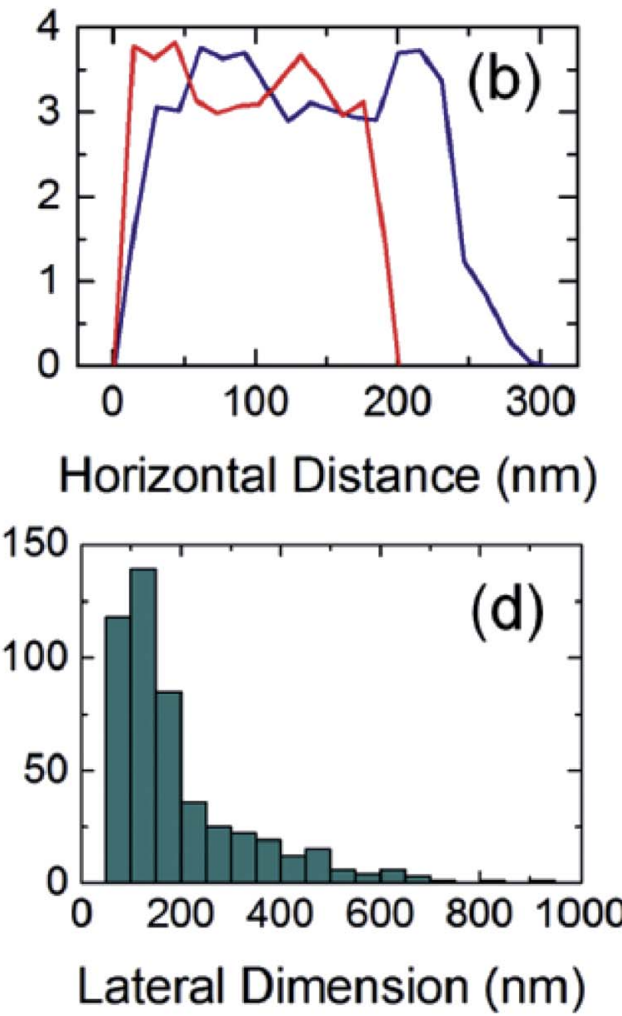

Fig. 6 Atomic force microscopy characterization of dispersed graphene flakes: (a) image and (b) section of a typical graphene flake. Distributions of (c) flake thickness and (d) flake lateral dimensions [reprinted with permission from ref. 77, D. Dodoo-Arhin, R. C. T. Howe, G. Hu, Y. Zhang, P. Hiralal, A. Bello, G. Amaratunga and T. Hasan, Inkjet-printed graphene electrodes for dye-sensitized solar cells, Carbon, 2016, 105, 33-41. Copyright@ Elsevier]. 


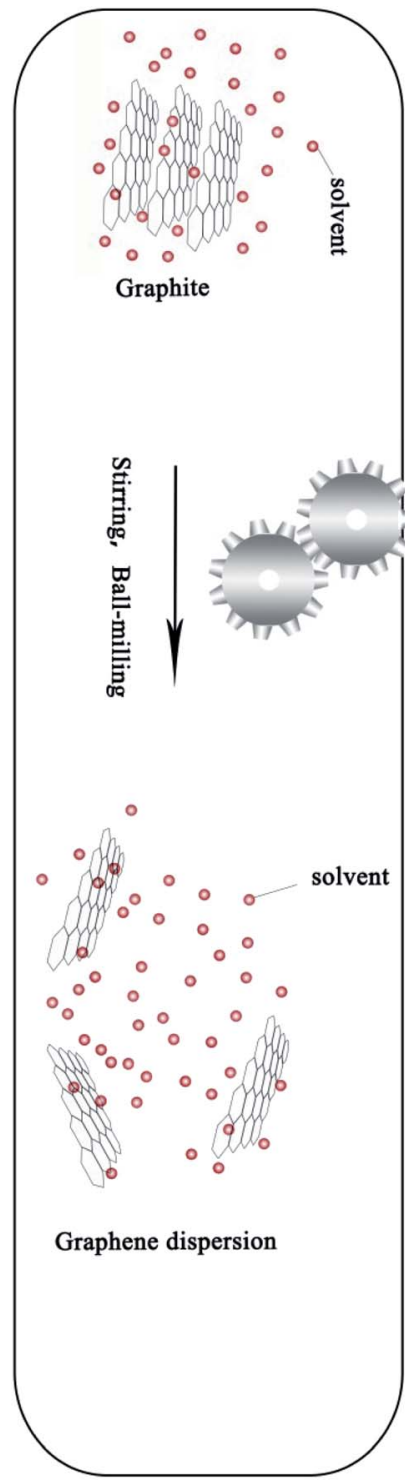

Physical Dispersion Methods
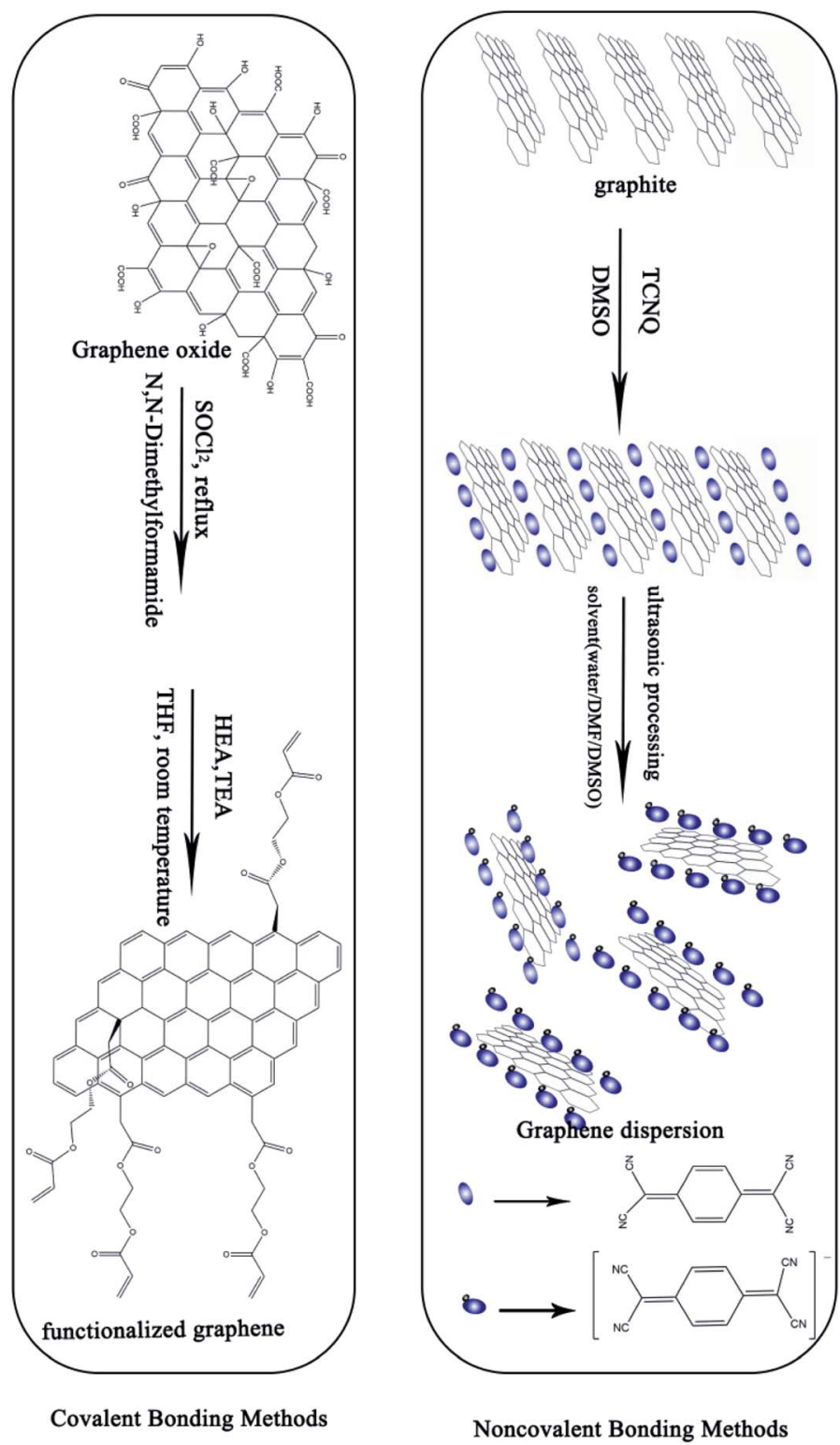

Fig. 7 Schematic diagram of the dispersion methods used for graphene.

be divided into three categories, namely physical dispersion methods, noncovalent bonding methods and covalent bonding methods (Fig. 7).

Physical methods encompass ultrasonic treatment, stirring, and ball-milling. Baomin Wang et al. ${ }^{84}$ prepared a graphene nanoplatelet suspension by ultrasonic treatment. They used a minimum sonication time to effectively disperse the $0.1 \mathrm{~g} \mathrm{~L}^{-1}$ concentration of bundled graphene nanoplatelets. Weifeng Zhao et al. ${ }^{85}$ used ball-milling to exfoliate graphene in a variety of organic solvents such as $N, N$-dimethylformamide, at a concentration of up to $0.08 \mathrm{mg} \mathrm{mL}^{-1}$, achieving a yield higher than $32.0 \mathrm{wt} \%$. With low cost, simple operation and the possibility of application to large scale production, physical methods are a popular choice among many researchers. However, physical methods cause damage to the structure of graphene and produce a low dispersion rate which is unsatisfactory.
Noncovalent bonding methods based on $\pi-\pi$ interactions and surfactant modification can form a stable dispersion of graphene. $\pi-\pi$ interactions make use of $\pi$ bonds in aromatic molecules (polycyclic aromatic hydrocarbons (PAHs), peptides, etc.) to stabilize the graphene dispersion. Jun Wang et al. ${ }^{77}$ prepared a kind of graphene dispersion using PAHs. They revealed that after loading with PAHs, the conformation and aggregation of the graphene and GO nanosheets dramatically changed. Surfactant addition is the most common way to prepare stable graphene dispersions. To prepare stable conductive ink various surfactants such as PAH and sodium dodecyl sulfate (SDS) ${ }^{\mathbf{8 6}}$ are needed together with a solvent like water or $N$-methylpyrrolidone, etc. Song et al. ${ }^{87}$ prepared a kind of graphene ink powder containing graphene and excess ethyl cellulose $(2: 3, \mathrm{w} / \mathrm{w})$ dispersed in terpineol with $20 \% \mathrm{w} / \mathrm{v}$ of solid in the solvent. They used this graphene 


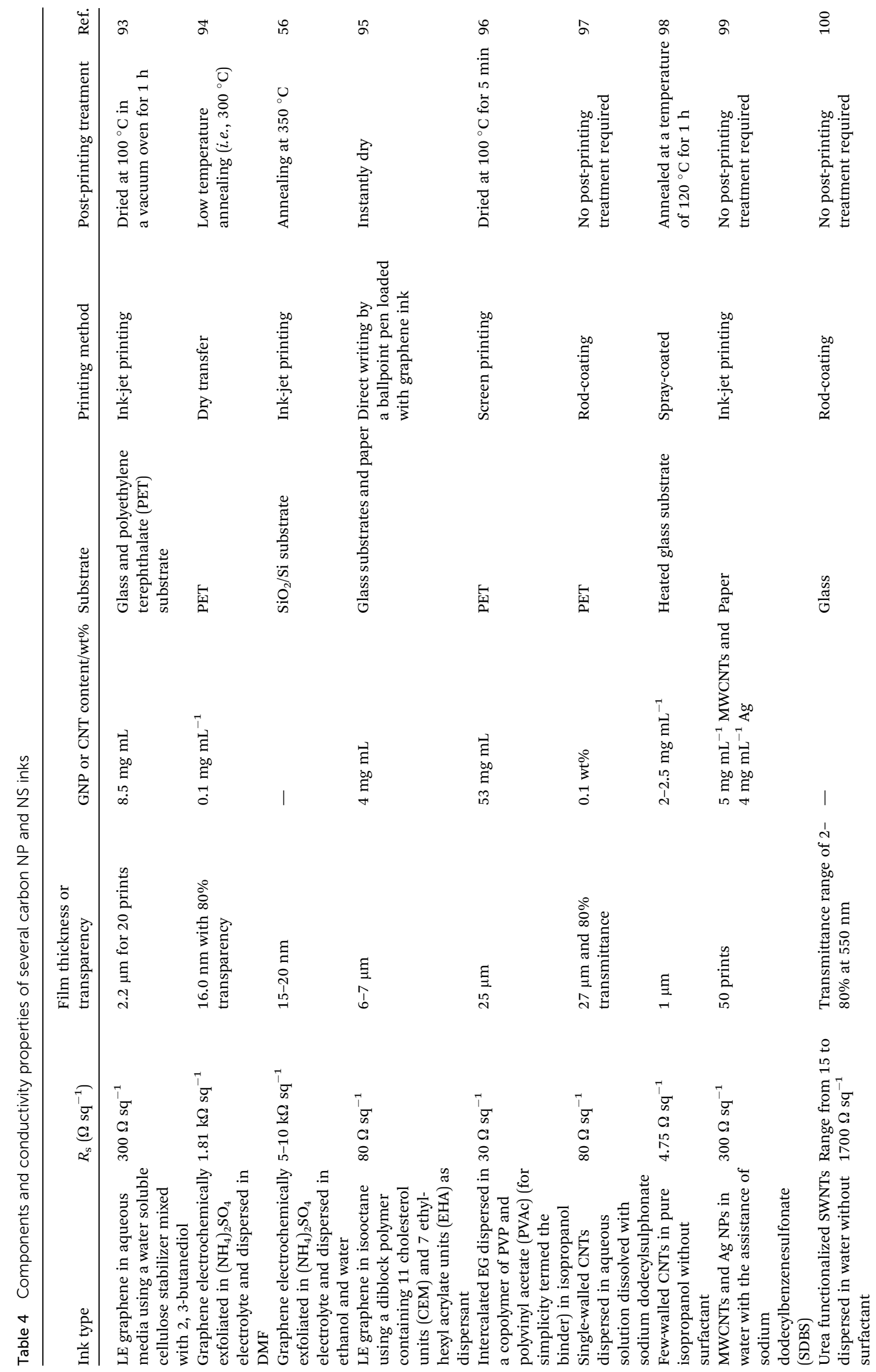


ink to print conductive graphene patterns on plastic with highresolution (3.2 $\mu \mathrm{m}$ line width and $1 \mu \mathrm{m}$ spacing) using a transfer printing method. In addition, carbon NSs and NPs will not melt during heat treatment, in contrast to metal NPs, but the dispersants existing in the carbon NSs and NPs need heat treatment for removal. Secor et al. ${ }^{88}$ heat treated graphene ink at $250{ }^{\circ} \mathrm{C}$ for 30 minutes to achieve a resistance of 4 $\mathrm{m} \Omega \mathrm{cm}$. Lee et $a{ }^{89}{ }^{\mathbf{8 9}}$ reported that sintering printed graphene NSs (GNSs) at $400{ }^{\circ} \mathrm{C}$ could effectively lead to the elimination of excess SDS on the GNSs and increase the $\mathrm{C}=\mathrm{C}$ content. However, these organic solvents are toxic. Developing nontoxic stabilizing agents and surfactants or modified graphene or CNTs with excellent dispersivity in water has become the subject of many studies in the literature. Michel et al. ${ }^{\mathbf{9 0}}$ synthesized a kind of surfactant-free graphene ink in a mixture of terpineol and cyclohexanone. Furthermore, the conductive ink had an excellent electrical conductivity with a resistance of only $1.1 \mathrm{~m} \Omega \mathrm{m}$ compared with $7.1 \mathrm{~m} \Omega \mathrm{m}$ for the surfactantassisted ink ( $N$-methyl-2-pyrrolidone and ethyl cellulose). This formulation is very eco-friendly and has excellent conductivity because of the biomaterials, terpineol and cyclohexanone. Koutsioukis et al. ${ }^{91}$ recently developed a highly conductive formulation using pristine graphene and dihydroxyphenyl-functionalized MWNTs mixed with another hydrophilic polymer which displayed desirable conductivity $\left(R_{\mathrm{s}}=22.6 \Omega \mathrm{sq}^{-1}, \sigma=4971 \mathrm{~S} \mathrm{~m}^{-1}\right)$.

Covalent bonding methods are most commonly used to functionalize graphene and CNTs. Attachment of a large number of hydroxyl, epoxy, carboxyl, or carbonyl groups to the surface of GO significantly improves the solubility and dispersion stability of the graphene in most common organic solvents.

2.3.5 Electrical conductivity of carbonaceous nanomaterials. It is widely believed that the low electrical conductivity of carbonaceous nanomaterials constrains their application. Commonly, charge transport mechanisms are mainly divided into two categories, namely particle contact and the tunnel effect. Key factors that determine the integrity and degree of compactness of a conducting circuit are the number of contacting particles, and the distance between the conductive particles. The realization of high conductivity conductive inks is closely related to the content, shape, size and polarity of the conductive fillers. Generally conductive materials that are small in size but large in specific surface area are the best candidate for conductive fillers. Therefore, when CNTs with slender fibrous structures and nanoflake graphene materials are chosen as conductive materials, good dispersibility and stability are crucial to the conductivity. At present, many reports are focusing on improving the conductivity of carbonaceous nanomaterials. Table 4 shows the components, conductivity properties and printing methods of several carbon NP inks. Overgaard et al. ${ }^{92}$ demonstrated a method for highly conductive semitransparent graphene. Circuits using screen-printing had a low sheet resistance of $327 \Omega \mathrm{sq}^{-1}$ for thin semitransparent layers and $37 \%$ transmittance. Some researchers have combined carbonaceous nanomaterials with other conductive materials to get higher conductivity. Koutsioukis et al. ${ }^{91}$ synthesized a kind of highly conductive water-based polymer/ graphene nanomaterial. A conductive ink with a $22.6 \Omega \mathrm{sq}^{-1}$ sheet resistivity and $6459 \mathrm{~S} \mathrm{~m}^{-1}$ conductivity was obtained.

\section{Applications in intelligent food packaging}

As shown in Fig. 8, IFP technologies can mainly be divided into two categories, one which encompasses diagnostic technologies (time-temperature integrators/indicators, gas indicators, freshness indicators, bacteria indicators, etc.) and the other which encompasses communicating technologies (rapid frequency identification (RFID) tags, electronic article surveillance (EAS) tags, electro-magnetic identification (EMID) tags, etc.). ${ }^{101}$

\subsection{Diagnostic technologies in IFP using PE}

In the diagnostic technologies, printed sensors are usually used as indicators to detect the inner environment of the food packaging. ${ }^{\mathbf{1 - 4 9 3}}$ Printed sensors offer potential to improve efficiency without expensive equipment, and have been studied in lots of research. However, there are still some obstacles to be overcome: the sensors must be lightweight and flexible, production costs need to be decreased, sensitivity needs to be increased and the sensors must be eco-friendly. ${ }^{\mathbf{1 0 2}}$

Flexible printed sensors for food monitoring are complex integrated systems, which are typically composed of: (1) conducting electrodes based on conductive ink, (2) flexible/ stretchable substrates, such as PI, PET, PEN, and (3) sensing materials. Fig. 9 shows the diagram of a flexible gas sensor in an IFP system. The sensing materials can monitor the environment inside of the package. The chemical signal can be changed into an electrical one by an electrode printed with effective

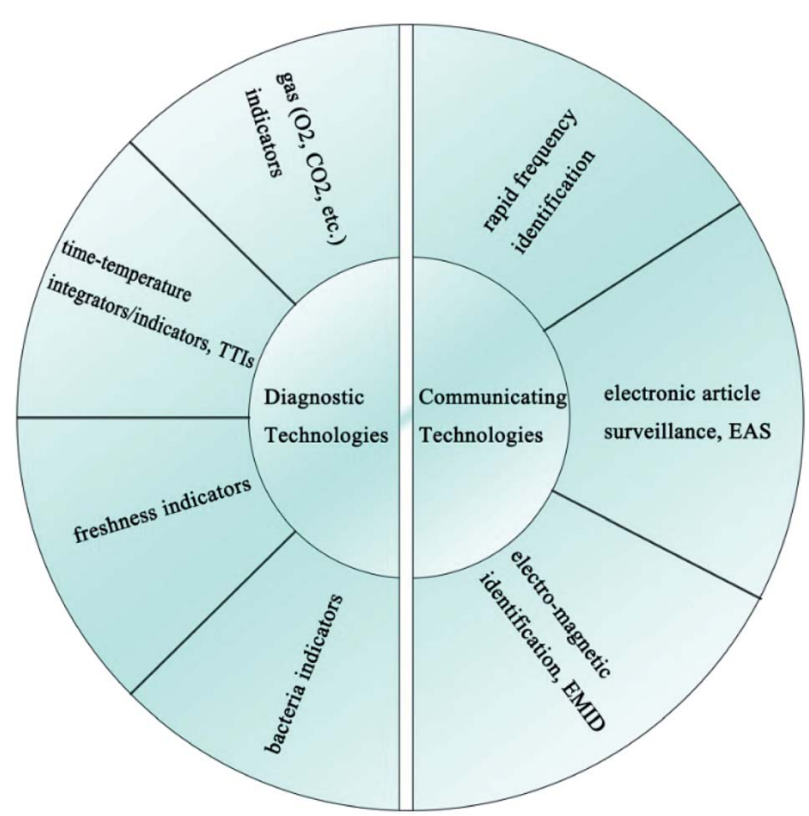

Fig. 8 The main categories of IFP technologies 
conductive ink. The following section presents several flexible sensors that can be applied to IFP.

3.1.1 Gas sensors. A reduction or increase in water content, oxidation reactions and aerobic microorganisms accelerate food decay. ${ }^{\mathbf{1 0 3 - 1 0 5}}$ The content of the air (two or three constituents out of carbon dioxide $\left(\mathrm{CO}_{2}\right)$, oxygen $\left(\mathrm{O}_{2}\right)$ and nitrogen $\left.\left(\mathrm{N}_{2}\right)\right)$ and the humidity in the packaging should be adjusted according to the food being packaged and the requirements for freshness. $\mathrm{CO}_{2}$ is a kind of gas bacteriostat-a low concentration of $\mathrm{CO}_{2}$ promotes microbiological reproduction, and a high concentration of $\mathrm{CO}_{2}$ can inhibit the growth and reproduction of most aerobic bacteria that cause food decay. ${ }^{\mathbf{1 0 6}}$ The concentration of $\mathrm{O}_{2}$ should be kept low in food packaging to reduce both the respiration of fresh fruits and vegetables and the oxidation of food, although a high $\mathrm{O}_{2}$ content retains the color of fresh meat. An inert gas like $\mathrm{N}_{2}$ which does not react with food can reduce the oxidation rate of fats and aromatics in food. Table 5 (ref. 107) shows the recommended content of gases in the packaging of various foods.

Gas sensors are usually fabricated so that chemical reactions or changes in acidity lead to physical changes, for example, a change in resistance. ${ }^{108}$ They are crucial for controlling and recording changes in gas content and contribute to the extension of product shelf life. For example, Vargas-Sansalvador et $a .^{109}$ reported the development of a water-based ionic liquid $\mathrm{CO}_{2}$ sensor which can be printed on food packaging. The
Table 5 Recommendation content of gases in the packaging of various foods

\begin{tabular}{llll}
\hline Type of food & $\mathrm{O}_{2}(\%)$ & $\mathrm{CO}_{2}(\%)$ & $\mathrm{N}_{2}(\%)$ \\
\hline Red meat & $60-85$ & $15-40$ & - \\
Cooked meat/bacon & - & $20-35$ & $65-80$ \\
Poultry & - & 25 & 75 \\
Lean fish & - & 40 & 30 \\
Oily fish & & 60 & 40 \\
Salmon & - & 60 & 20 \\
Hard cheese & - & 100 & - \\
Soft cheese & - & 30 & 70 \\
Bread & - & $60-70$ & $30-40$ \\
Milk free cake & - & 60 & 40 \\
Dairy cake & - & - & 100 \\
Fresh spaghetti & $3-5$ & - & 100 \\
Fruit and vegetables & & $3-5$ & $85-95$ \\
\end{tabular}

sensor had an excellent optical performance and was especially sensitive to low concentrations of $\mathrm{CO}_{2}$. Lang and Jedermann ${ }^{\mathbf{1 1 0}}$ demonstrated the detection of gas content in packaging for various gases such as $\mathrm{O}_{2}, \mathrm{CO}_{2}$, alcohols and so on. S. Santoro et al. ${ }^{111}$ prepared an $\mathrm{O}_{2}$ sensor based on the immobilization of tris-1,10-phenanthroline ruthenium which was printed onto a food packaging material to monitor oxygen permeation. This kind of sensor could also be used as a leakage indicator.
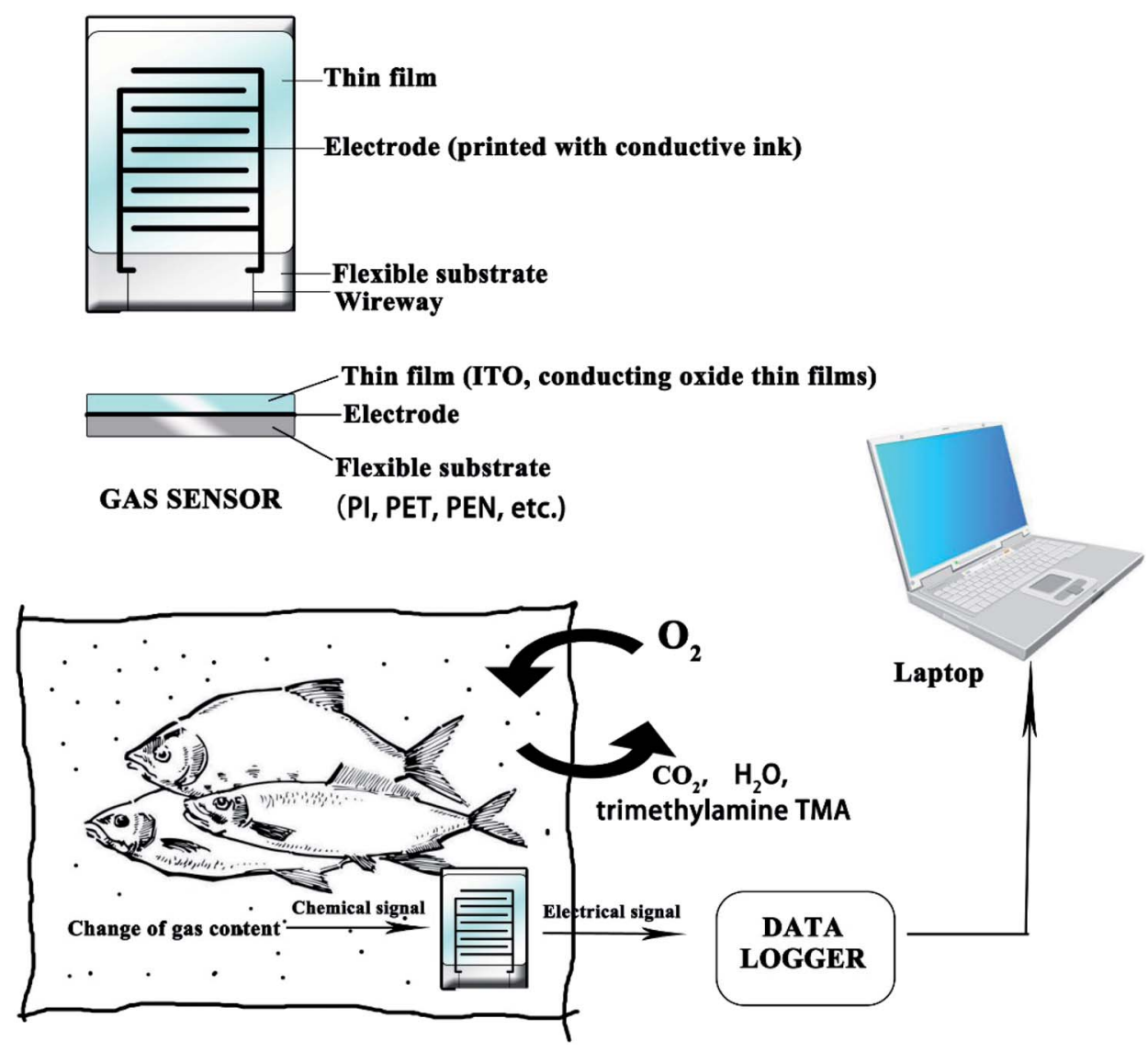

Fig. 9 A diagram of an IFP system based on gas sensors. 


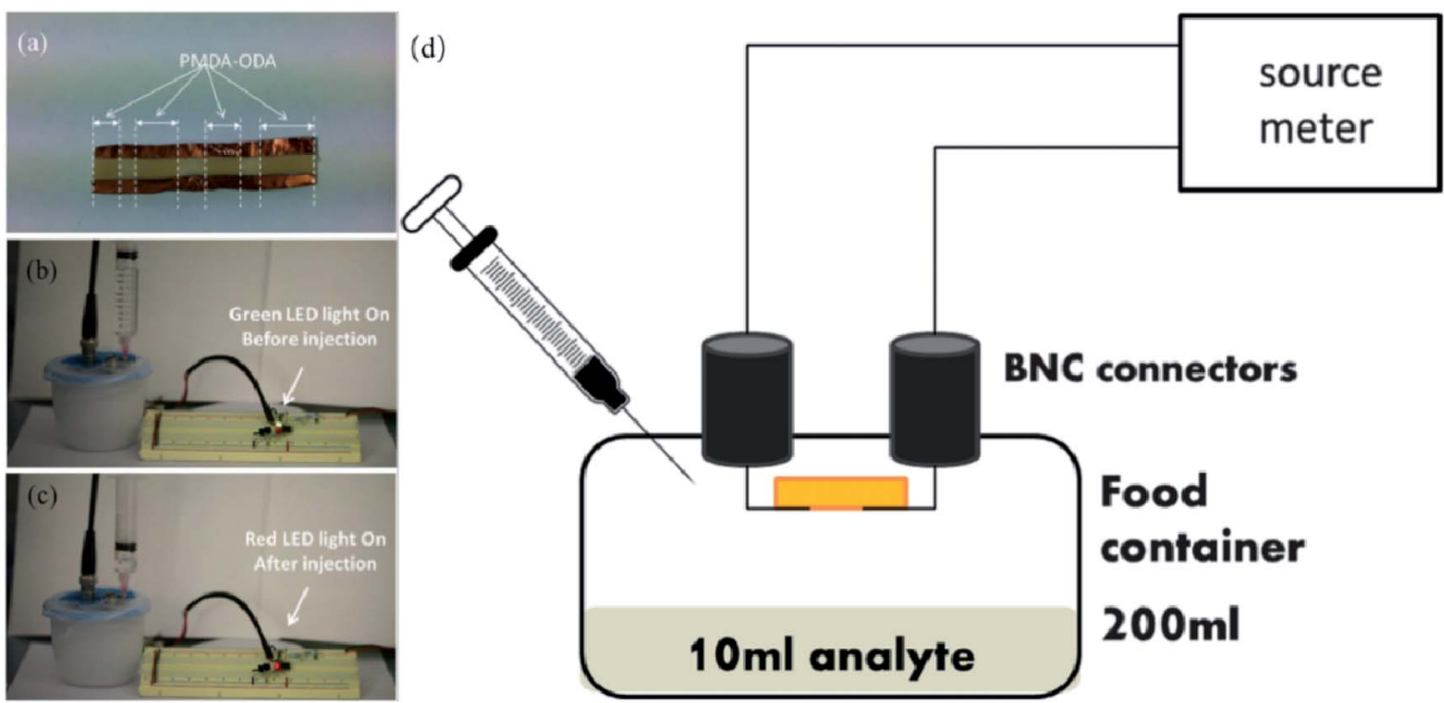

Fig. $10 \mathrm{An} \mathrm{NH}_{3}$ sensor based on pyromellitic dianhydride-4,4-oxydianiline. (a) The darker parts of cotton is the cured polymer. (b) Before injection of $\mathrm{NH}_{3}$ solution the green led is on. (c) After the injection of $\mathrm{NH}_{3}$ solution the red led turns on. (d) Schematic representation of the experimenting set-up [adapted from ref. 112, E. L. Papadopoulou, D. Morselli, M. Prato, A. Barcellona, A. Athanassiou and I. S. Bayer, An efficient pure polyimide ammonia sensor, Journal of Materials Chemistry C, 2016, 4, 7790-7797. Copyright@ Royal Society of Chemistry].

Papadopoulou ${ }^{112}$ obtained a highly sensitive ammonia $\left(\mathrm{NH}_{3}\right)$ gas sensor for food packaging technology based on pyromellitic dianhydride-4,4-oxydianiline, as shown in Fig. 10. When an $\mathrm{NH}_{3}$-releasing solution is injected into the package, the signal indicator of the sensor changes from blue to red. As the freshness of meat is closely related to the change of $\mathrm{NH}_{3}$ content in the packaging, this sensor would provide a technology for a realtime display of freshness of packaged meat.

3.1.2 Sensors for detecting food decay. Food quality changes can be broken down into two types: microbial metabolites such as toxins, gases, smells and mucus can lead to $\mathrm{pH}$

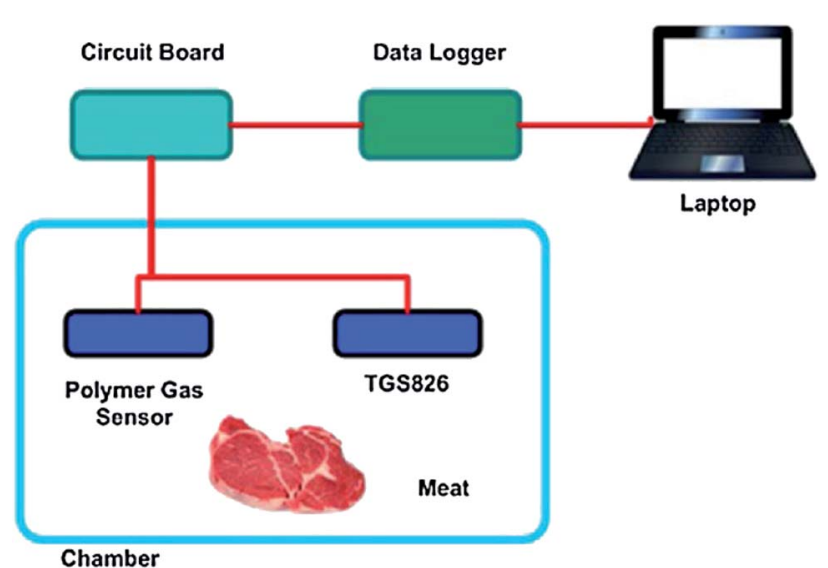

Fig. 11 A schematic representation of an IFP system for monitoring $\mathrm{NH}_{3}$ gas in a chamber [reprinted with permission from ref. 121, S. Matindoust, A. Farzi, M. Baghaei Nejad, M. H. Shahrokh Abadi, Z. Zou and L.-R. Zheng, Ammonia gas sensor based on flexible polyaniline films for rapid detection of spoilage in protein-rich foods, Journal of Materials Science: Materials in Electronics, 2017, 28, 7760-7768. Copyright@ Springer Nature]. changes that cause food decay; and fat and pigment oxidation can have a negative effect on food flavor. ${ }^{113-115}$ Food decay is detected by the reaction of the microbial metabolites (organic acids, ethanol, volatile nitrogen compounds and biogenic amines) with components contained in chemical sensors. ${ }^{116-118}$ For example, a titania nanotubular sensor was successfully fabricated on a printed circuit board for the detection of food decay products including dimethyl sulfide from decayed eggs and ethyl acetate from decayed tomatoes. Schaude et al. ${ }^{119}$ fabricated a kind of colorimetric sensor for $\mathrm{NH}_{3}$ and biogenic amines in packaging. They selected a $\mathrm{pH}$ sensitive dye as the indicator which is induced to change color from green to red when it is exposed to amines during food spoilage. Alreshaid et al. ${ }^{120}$ reviewed the gas sensors which can detect certain gases to determine the freshness of packaged foods. Matindoust et al..$^{121}$ also developed an $\mathrm{NH}_{3}$ gas sensor printed on flexible polyaniline films for protein-rich foods. Fig. 11 shows this IFP system for detecting $\mathrm{NH}_{3}$ gas. The voltage of the electrodes through the film is directly proportional to the time and the gas concentration; chemical signals are changed into electrical ones.

Recently, biosensors have also been used to indicate freshness. ${ }^{122}$ Biosensors are made up of biological components (enzymes, ${ }^{123}$ antibodies ${ }^{124}$ and cells) and physical components that can decode the biological signal and change it to a physical one. ${ }^{125}$ Yang et al. presented some different CNT-based biosensors. ${ }^{126}$ For example, enzyme CNT-based biosensors were mentioned in their review. The large specific surface area of CNTs promotes enzyme conjugation so that such sensors can detect glucose and protein by bioreaction. A kind of highly efficient biosensor for glucose detection based on $\mathrm{ZnO} / \mathrm{ZnS}$ core/shell nanotube arrays (CSNAs) was fabricated by Tarish et al. ${ }^{127}$ They demonstrated a method in which their 
$\mathrm{ZnO} / \mathrm{ZnS}$ CSNA electrode gave a higher sensing performance than other reported sensors.

\subsection{Communicating technologies in IFP using PEs}

RFID technologies are unlike sensors and indicators and fall into another category. RFID tags contain transponders and antennas, satisfying the need of consumers for transparency in the supply chain and providing necessary and effective data for the production and sales decision-makers. ${ }^{\mathbf{4 , 1 0 1 , 1 2 8 , 1 2 9}}$ Direct inkjet printing of antennas on plastic and paper substrates with the use of conductive NP inks is a promising approach to the production of low-cost RFID tags. RFID tags have broad application prospects for the following reasons: (i) they offer a large storage capacity (one to thousands of bytes); (ii) their readable distance through a scanner has a wide range (from a few centimeters to about two hundred meters); (iii) they can be operated without contact, and no particular angle is needed to read information; (iv) they are readable in diverse conditions (even in the dark or under water); and (v) they are recyclable. ${ }^{129,130}$ However, the biggest disadvantage of RFID is its cost, which is a stumbling block to wide-spread commercialization. Using RFID tags in IFP, the link of the supply chain at which the food begins to corrupt can be identified and RFID can speed customer checkout by recognition technology. Recently, many companies have started to use this technology to build a bridge between supermarkets, suppliers and consumers. Suppliers label their goods with RFID tags and once the goods reach the store center of the supermarket, the product labels are immediately scanned and the ID numbers are stored. When customers buy commodities, the ID numbers are deleted from the list of shelf products.

Recently more intelligent RFID tags have been developed, such as sensor-enabled RFID tags to provide information on humidity and temperature. Borgese et al. ${ }^{131}$ fabricated a novel chipless RFID humidity sensor by inkjet printing. Variations in the relative humidity level from $50 \%$ to $90 \%$ gave a frequency shift of up to $270 \mathrm{MHz}$. It was based on a finite artificial impedance surface. Lorite et al. ${ }^{129}$ presented an RFID-assisted critical temperature indicator for supply chain monitoring using R2R printing. When the critical temperature that was detrimental to food storage was reached, the resistance rapidly increased (from $1 \mathrm{k} \Omega$ to $8 \mathrm{k} \Omega$ ).

\section{Outlook}

PE offers wide application prospects in IFP as discussed. However, there are still some challenges and problems to be solved. The following goals remain: (i) decreasing the cost; (ii) simplifying production processes and increasing throughput; (iii) further diversifying applications in IFP; and (iv) developing eco-friendly raw materials with better properties.

Conductive ink plays a crucial role in PE. Optimizing the properties of conductive ink is still a driving force in many literature reports. Nowadays, high-cost Ag ink is still universal in commercially available ink. Therefore, many researchers are focusing on developing low-cost alternative $\mathrm{Cu}, \mathrm{Al}$, and $\mathrm{Ni}$ nanomaterials with better properties. However, these types of nanomaterials are easily oxidized, causing deterioration of conductivity so researchers are searching for effective methods to stabilize these nanomaterials against oxidation. The addition of stabilizers is one common approach being considered; a second recent approach is to hinder oxidation of the NPs by, for example, synthesizing NPs with a dense shell that gives them antioxidant properties. Sintering is a key process for improving conductivity. Researchers are developing new sintering methods that avoid destruction of plastic or flexible substrates. For example, low temperature sintering has been studied recently. Low-cost carbonaceous materials are always considered as good candidates for metal-based conductive inks. However, their lower conductivity compared to that of metal NPs is a drawback. Some researchers still consider carbonaceous materials to offer the most prospects because many literature reports describe effective methods to improve their conductivity.

It should be noted that PE integrated with IFP has recently led to more effective functions to protect products. Various sensors for monitoring the changes in food and the inner environment of food packaging have been fabricated. RFID tags satisfy the present market, offering supply chain transparency and providing more information to retailers and manufacturers. However, the cost of RFID is indeed a big obstacle for further application. Developing lower-cost RFID tags with long service lives compatible with the shelf lives of products is still a burning issue. The application of RFID tags could be expanded for example through sensor-enabled RFID tags.

One more important application of $\mathrm{PE}$ is in flexible batteries and IFP displays. Nowadays, small volume batteries printed on flexible substrates as capacitors for high energy storage density together with flexible displays have been used to diversify packaging functions.

In this review, we have discussed issues from conductive ink synthesis to PE application to IFP, with the help of some reported articles. We trust that this review may help readers to better understand the preparation of conductive inks and the application of PE to IFP.

\section{Conflicts of interest}

The authors declare that they have no conflicts of interest.

\section{Acknowledgements}

The authors gratefully acknowledge the financial support offered by the National Natural Science Foundation of China (Grant No. 51371129 and 1114226).

\section{References}

1 A. R. De Jong, H. Boumans, T. Slaghek, J. Van Veen, R. Rijk and M. Van Zandvoort, Active and intelligent packaging for food: is it the future?, Food Addit. Contam., 2005, 22, 975979. 
2 J. P. Kerry, M. N. O'Grady and S. A. Hogan, Past, current and potential utilisation of active and intelligent packaging systems for meat and muscle-based products: a review, Meat Sci., 2006, 74, 113-130.

3 C. E. Realini and B. Marcos, Active and intelligent packaging systems for a modern society, Meat Sci., 2014, 98, 404-419.

4 N. Bumbudsanpharoke and S. Ko, Nanomaterial-based optical indicators: promise, opportunities, and challenges in the development of colorimetric systems for intelligent packaging, Nano Res., 2018, 12, 489-500.

5 X. Dai, W. Xu, T. Zhang, H. Shi and T. Wang, Room temperature sintering of $\mathrm{Cu}-\mathrm{Ag}$ core-shell nanoparticles conductive inks for printed electronics, Chem. Eng. J., 2019, 364, 310-319.

6 A. Kamyshny and S. Magdassi, Conductive Nanomaterials for Printed Electronics, Small, 2014, 10, 3515-3535.

7 A. Kamyshny and S. Magdassi, Conductive nanomaterials for 2D and 3D printed flexible electronics, Chem. Soc. Rev., 2019, 48, 1712-1740.

8 L. He and S. C. Tjong, Nanostructured transparent conductive films: fabrication, characterization and applications, Mater. Sci. Eng., R, 2016, 109, 1-101.

$9 \mathrm{~W}$. Yang and C. Wang, Graphene and the related conductive inks for flexible electronics, J. Mater. Chem. C, 2016, 4, 71937207.

10 B. Tian, W. Yao, P. Zeng, X. Li, H. Wang, L. Liu, Y. Feng, C. Luo and W. Wu, All-printed, low-cost, tunable sensing range strain sensors based on $\mathrm{Ag}$ nanodendrite conductive inks for wearable electronics, J. Mater. Chem. C, 2019, 7, 809-818.

11 G. Mattana, A. Loi, M. Woytasik, M. Barbaro, V. Noël and B. Piro, Inkjet-Printing: A New Fabrication Technology for Organic Transistors, Adv. Mater. Technol., 2017, 2.

$12 \mathrm{~W}$. Wu, Inorganic nanomaterials for printed electronics: a review, Nanoscale, 2017, 9, 7342-7372.

13 Y. Liao, R. Zhang, H. Wang, S. Ye, Y. Zhou, T. Ma, J. Zhu, L. D. Pfefferle and J. Qian, Highly conductive carbonbased aqueous inks toward electroluminescent devices, printed capacitive sensors and flexible wearable electronics, RSC Adv., 2019, 9, 15184-15189.

14 G. Cummins and M. P. Y. Desmulliez, Inkjet printing of conductive materials: a review, Circuit World, 2012, 38, 193-213.

15 H. J. Gysling, Nanoinks in inkjet metallization - Evolution of simple additive-type metal patterning, Curr. Opin. Colloid Interface Sci., 2014, 19, 155-162.

16 S. I. Na, Y. H. Seo, Y. C. Nah, S. S. Kim, H. Heo, J. E. Kim, N. Rolston, R. H. Dauskardt, M. Gao, Y. Lee and D. Vak, High Performance Roll-to-Roll Produced Fullerene-Free Organic Photovoltaic Devices via Temperature-Controlled Slot Die Coating, Adv. Funct. Mater., 2018, 29.

17 S. Barui, S. Mandal and B. Basu, Thermal inkjet 3D powder printing of metals and alloys: current status and challenges, Current Opinion in Biomedical Engineering, 2017, 2, 116-123.
18 Z. Chu, J. Peng and W. Jin, Advanced nanomaterial inks for screen-printed chemical sensors, Sens. Actuators, B, 2017, 243, 919-926.

19 W. Li, X. Xu, W. Li, Y. Zhao and M. Chen, Green synthesis of micron-sized silver flakes and their application in conductive ink, J. Mater. Sci., 2018, 53, 6424-6432.

20 L. Mo, Z. Guo, L. Yang, Q. Zhang, Y. Fang, Z. Xin, Z. Chen, K. Hu, L. Han and L. Li, Silver Nanoparticles Based Ink with Moderate Sintering in Flexible and Printed Electronics, Int. J. Mol. Sci., 2019, 20.

21 Y. Li, M. Roundhill, M. Yang, I. Pavlovsky, R. L. Fink and Z. Yaniv, Photo-curing process for metallic inks, US Pat., US20090311440A1, Aug. 8, 2017.

22 M. Layani, A. Kamyshny and S. Magdassi, Transparent conductors composed of nanomaterials, Nanoscale, 2014, 6, 5581-5591.

23 L. Polavarapu, K. K. Manga, H. D. Cao, K. P. Loh and Q.-H. Xu, Preparation of Conductive Silver Films at Mild Temperatures for Printable Organic Electronics, Chem. Mater., 2011, 23, 3273-3276.

24 L. Polavarapu, K. K. Manga, K. Yu, P. K. Ang, H. D. Cao, J. Balapanuru, K. P. Loh and Q. H. Xu, Alkylamine capped metal nanoparticle "inks" for printable SERS substrates, electronics and broadband photodetectors, Nanoscale, 2011, 3, 2268-2274.

25 Y. Wang, X. Li, J. Luo, J. Zhang, W. Jianjun and Y. Tang, Fabrication of $\mathrm{Ag}$ nanocluster and adjustment of particle size by plasma vapor deposition, High Power Laser Part. Beams, 2014, 26(08), 26082001.

26 K. Gerasopoulos, E. Pomerantseva, M. McCarthy, A. Brown, C. Wang, J. Culver and R. Ghodssi, Hierarchical threedimensional microbattery electrodes combining bottomup self-assembly and top-down micromachining, ACS Nano, 2012, 6, 6422-6432.

27 F. Hoeng, J. Bras, E. Gicquel, G. Krosnicki and A. Denneulin, Inkjet printing of nanocellulose-silver ink onto nanocellulose coated cardboard, $R S C A d v$., 2017, 7, 15372-15381.

28 S. S. Narwade, B. B. Mulik, S. M. Mali and B. R. Sathe, Silver nanoparticles sensitized C60(Ag@C60) as efficient electrocatalysts for hydrazine oxidation: implication for hydrogen generation reaction, Appl. Surf. Sci., 2017, 396, 939-944.

29 A. Pajor-Świerzy, Y. Farraj, A. Kamyshny and S. Magdassi, Effect of carboxylic acids on conductivity of metallic films formed by inks based on copper@silver core-shell particles, Colloids Surf., A, 2017, 522, 320-327.

30 K. Ranoszek-Soliwoda, E. Tomaszewska, E. Socha, P. Krzyczmonik, A. Ignaczak, P. Orlowski, M. Krzyzowska, G. Celichowski and J. Grobelny, The role of tannic acid and sodium citrate in the synthesis of silver nanoparticles, J. Nanopart. Res., 2017, 19, 273.

31 T. Jayaramudu, G. M. Raghavendra, K. Varaprasad, G. V. S. Reddy, A. B. Reddy, K. Sudhakar and E. R. Sadiku, Preparation and characterization of poly(ethylene glycol) stabilized nano silver particles by a mechanochemical assisted ball mill process, J. Appl. Polym. Sci., 2016, 133. 
32 K. Afshinnia, M. Sikder, B. Cai and M. Baalousha, Effect of nanomaterial and media physicochemical properties on $\mathrm{Ag}$ NM aggregation kinetics, J. Colloid Interface Sci., 2017, 487, 192-200.

$33 \mathrm{~S} . \mathrm{Mu}, \mathrm{W}$. Liu, L. Zhao, Y. Long and H. Gu, Antimicrobial AgNPs composites of gelatin hydrogels crosslinked by ferrocene-containing tetrablock terpolymer, Polymer, 2019, 169, 80-94.

34 G. V. Kurlyandskaya, I. P. Novoselova, V. V. Schupletsova, R. Andrade, N. A. Dunec, L. S. Litvinova, A. P. Safronov, K. A. Yurova, N. A. Kulesh, A. N. Dzyuman and I. A. Khlusov, Nanoparticles for magnetic biosensing systems, J. Magn. Magn. Mater., 2017, 431, 249-254.

35 S. M. Louie, J. M. Gorham, J. Tan and V. A. Hackley, Ultraviolet photo-oxidation of polyvinylpyrrolidone (PVP) coatings on gold nanoparticles, Environ. Sci.: Nano, 2017, 4.

36 M. Yu, Y. Han, J. Li and L. Wang, One-step synthesis of sodium carboxymethyl cellulose-derived carbon aerogel/ nickel oxide composites for energy storage, Chem. Eng. J., 2017, 324, 287-295.

37 C. Joanna, L. Marcin, K. Ewa and P. Grazyna, A nonspecific synergistic effect of biogenic silver nanoparticles and biosurfactant towards environmental bacteria and fungi, Ecotoxicology, 2018, 27, 352-359.

38 M. Seo, J. S. Kim, J. G. Lee, S. B. Kim and S. M. Koo, The effect of silver particle size and organic stabilizers on the conductivity of silver particulate films in thermal sintering processes, Thin Solid Films, 2016, 616, 366-374.

39 C. Cheng, J. Li, T. Shi, X. Yu, J. Fan, G. Liao, X. Li, S. Cheng, Y. Zhong and Z. Tang, A novel method of synthesizing antioxidative copper nanoparticles for high performance conductive ink, J. Mater. Sci.: Mater. Electron., 2017, 28, 13556-13564.

40 C. Yim, Z. A. Kockerbeck, S. B. Jo and S. S. Park, Hybrid Copper-Silver-Graphene Nanoplatelet Conductive Inks on PDMS for Oxidation Resistance Under Intensive Pulsed Light, ACS Appl. Mater. Interfaces, 2017, 9, 37160-37165.

41 A. Pajor-Świerzy, Y. Farraj, A. Kamyshny and S. Magdassi, Air stable copper-silver core-shell submicron particles: Synthesis and conductive ink formulation, Colloids Surf., A, 2017, 521, 272-280.

42 M. Krivec, A. Roshanghias, A. Abram and A. Binder, Exploiting the combination of 3D polymer printing and inkjet Ag-nanoparticle printing for advanced packaging, Microelectron. Eng., 2017, 176, 1-5.

43 H. M. Cronin, Z. Stoeva, M. Brown, M. Shkunov and S. R. P. Silva, Photonic Curing of Low-Cost Aqueous Silver Flake Inks for Printed Conductors with Increased Yield, ACS Appl. Mater. Interfaces, 2018, 10, 21398-21410.

44 Y.-T. Kwon, Y.-I. Lee, S. Kim, K.-J. Lee and Y.-H. Choa, Full densification of inkjet-printed copper conductive tracks on a flexible substrate utilizing a hydrogen plasma sintering, Appl. Surf. Sci., 2017, 396, 1239-1244.

45 C. Ayyappadas, A. Muthuchamy, A. Raja Annamalai and D. K. Agrawal, An investigation on the effect of sintering mode on various properties of copper-graphene metal matrix composite, Adv. Powder Technol., 2017, 28, 17601768.

46 H. Koga, T. Inui, I. Miyamoto, T. Sekiguchi, M. Nogi and K. Suganuma, A high-sensitivity printed antenna prepared by rapid low-temperature sintering of silver ink, RSC Adv., 2016, 6, 84363-84368.

47 D. Kim and J. Moon, Highly Conductive Ink Jet Printed Films of Nanosilver Particles for Printable Electronics, Electrochem. Solid-State Lett., 2005, 8, 30-33.

48 S. Magdassi, M. Grouchko, O. Berezin and K. Alexander, Triggering the Sintering of Silver Nanoparticles at Room Temperature, ACS Nano, 2010, 4, 1943-1948.

49 A. Maattanen, P. Ihalainen, P. Pulkkinen, S. Wang, H. Tenhu and J. Peltonen, Inkjet-printed gold electrodes on paper: characterization and functionalization, ACS Appl. Mater. Interfaces, 2012, 4, 955-964.

50 Y. Mou, Y. Zhang, H. Cheng, Y. Peng and M. Chen, Fabrication of highly conductive and flexible printed electronics by low temperature sintering reactive silver ink, Appl. Surf. Sci., 2018, 459, 249-256.

51 Y. T. Kwon, Y. S. Kim, Y. Lee, S. Kwon, M. Lim, Y. Song, Y. H. Choa and W. H. Yeo, Ultrahigh Conductivity and Superior Interfacial Adhesion of a Nanostructured, Photonic-Sintered Copper Membrane for Printed Flexible Hybrid Electronics, ACS Appl. Mater. Interfaces, 2018, 10, 44071-44079.

52 Y. K. Lee, J. Kim, Y. Kim, J. W. Kwak, Y. Yoon and J. A. Rogers, Room Temperature Electrochemical Sintering of $\mathrm{Zn}$ Microparticles and Its Use in Printable Conducting Inks for Bioresorbable Electronics, Adv. Mater., 2017, 29.

53 S.-H. Park and H.-S. Kim, Flash light sintering of nickel nanoparticles for printed electronics, Thin Solid Films, 2014, 550, 575-581.

54 J.-H. Chu, S.-J. Joo and H.-S. Kim, Development of a via-hole connection process via intense pulsed light sintering with $\mathrm{Cu}$ micro/Ag nano-hybrid ink for a multi-layered flexible printed circuit board, Thin Solid Films, 2019, 680, 1-11.

55 C. Tang, H.-F. Wang, J.-Q. Huang, W. Qian, F. Wei, S.-Z. Qiao and Q. Zhang, 3D Hierarchical Porous Graphene-Based Energy Materials: Synthesis, Functionalization, and Application in Energy Storage and Conversion, Electrochemical Energy Reviews, 2019, 2, 332371.

56 E. Yakimchuk, R. Soots, I. Kotin and I. Antonova, 2D printed graphene conductive layers with high carrier mobility, Current Applied Physics, 2017, 17, 1655-1661.

57 J. Phiri, P. Gane and T. C. Maloney, General overview of graphene: production, properties and application in polymer composites, Mater. Sci. Eng., B, 2017, 215, 9-28.

58 A. K. Geim and K. S. Novoselov, The rise of graphene, Manchester Centre for Mesoscience and Nanotechnology, University of Manchester, Oxford Road M13 9PL, United Kingdom, 2009.

59 M. L. Yola, Development of Novel Nanocomposites Based on Graphene/Graphene Oxide and Electrochemical Sensor Applications, Curr. Anal. Chem., 2019, 15, 159-165. 
60 H. Hibino, S. Wang, C. M. Orofeo and H. Kageshima, Growth and low-energy electron microscopy characterizations of graphene and hexagonal boron nitride, Prog. Cryst. Growth Charact. Mater., 2016, 62, 155176.

61 H. Zheng, Y. Gan, P. Abbamonte and L. K. Wagner, Importance of sigma Bonding Electrons for the Accurate Description of Electron Correlation in Graphene, Phys. Rev. Lett., 2017, 119, 166402.

62 P. G. Karagiannidis, S. A. Hodge, L. Lombardi, F. Tomarchio, N. Decorde, S. Milana, I. Goykhman, Y. Su, S. V. Mesite, D. N. Johnstone, R. K. Leary, P. A. Midgley, N. M. Pugno, F. Torrisi and A. C. Ferrari, Microfluidization of Graphite and Formulation of Graphene-Based Conductive Inks, ACS Nano, 2017, 11, 2742-2755.

63 J. Li, H. Yan, D. Dang, W. Wei and L. Meng, Salt and water co-assisted exfoliation of graphite in organic solvent for efficient and large scale production of high-quality graphene, J. Colloid Interface Sci., 2019, 535, 92-99.

64 B. H. Nguyen and V. H. Nguyen, Promising applications of graphene and graphene-based nanostructures, Adv. Nat. Sci.: Nanosci. Nanotechnol., 2016, 7.

65 M. Yi and Z. Shen, Fluid dynamics: an emerging route for the scalable production of graphene in the last five years, RSC Adv., 2016, 6, 72525-72536.

66 S. N. Alam, N. Sharma and L. Kumar, Synthesis of Graphene Oxide (GO) by Modified Hummers Method and Its Thermal Reduction to Obtain Reduced Graphene Oxide (rGO)*, Graphene, 2017, 06, 1-18.

67 O. Jankovsky, M. Novacek, J. Luxa, D. Sedmidubsky, M. Bohacova, M. Pumera and Z. Sofer, Concentration of Nitric Acid Strongly Influences Chemical Composition of Graphite Oxide, Chemistry, 2017, 23, 6432-6440.

68 Y. Z. Wang, T. Chen, H. H. Liu, X. C. Wang and X. X. Zhang, Direct Liquid Phase Exfoliation of Graphite to Produce FewLayer Graphene by Microfluidization, J. Nanosci. Nanotechnol., 2019, 19, 2078-2086.

69 L. Huang, J. Pei, H. Jiang, C. Li and X. Hu, Electricity generation across graphene oxide membranes, Mater. Res. Bull., 2018, 97, 96-100.

70 M. L. Ould Ne, M. Boujnah, A. Benyoussef and A. E. Kenz, Electronic and Electrical Conductivity of $\mathrm{AB}$ and $\mathrm{AA}$ Stacked Bilayer Graphene with Tunable Layer Separation, J. Supercond. Novel Magn., 2016, 30, 1263-1267.

71 A. Ebdam, S. Jameh-Bozorghi, M. Yousefi and A. Niazi, Enhanced fire retardancy of polyvinylchloride by combination with graphene and magnesium hydroxide, Bulg. Chem. Commun., 2017, 152-158, Special Issue J.

72 K. Beltrop, S. Beuker, A. Heckmann, M. Winter and T. Placke, Alternative electrochemical energy storage: potassium-based dual-graphite batteries, Energy Environ. Sci., 2017, 10, 2090-2094.

$73 \mathrm{~J}$. Tian, L. Guo, X. Yin and W. Wu, The liquid-phase preparation of graphene by shear exfoliation with graphite oxide as a dispersant, Mater. Chem. Phys., 2019, 223, 1-8.
74 H. Shuai, Graphene Ink Fabricated Screen Printed Electrode for $\mathrm{Cd} 2+$ and Pd2+ Determination in Xiangjiang River, Int. J. Electrochem. Sci., 2016, 7430-7439, DOI: 10.20964/33 2016.09.387.

75 W. Ren and H. M. Cheng, The global growth of graphene, Nat. Nanotechnol., 2014, 9, 726-730.

76 H. Gao, K. Zhu, G. Hu and C. Xue, Large-scale graphene production by ultrasound-assisted exfoliation of natural graphite in supercritical $\mathrm{CO}_{2} / \mathrm{H}_{2} \mathrm{O}$ medium, Chem. Eng. J., 2017, 308, 872-879.

77 D. Dodoo-Arhin, R. C. T. Howe, G. Hu, Y. Zhang, P. Hiralal, A. Bello, G. Amaratunga and T. Hasan, Inkjet-printed graphene electrodes for dye-sensitized solar cells, Carbon, 2016, 105, 33-41.

78 A. O. Osikoya, O. Parlak, N. A. Murugan, E. D. Dikio, H. Moloto, L. Uzun, A. P. F. Turner and A. Tiwari, Acetylene-sourced CVD-synthesised catalytically active graphene for electrochemical biosensing, Biosens. Bioelectron., 2017, 89, 496-504.

79 K. Thodkar, D. Thompson, F. Luond, L. Moser, F. Overney, L. Marot, C. Schonenberger, B. Jeanneret and M. Calame, Restoring the Electrical Properties of CVD Graphene via Physisorption of Molecular Adsorbates, ACS Appl. Mater. Interfaces, 2017, 9, 25014-25022.

80 Y. Liu, B. Sun, J. Li, D. Cheng, X. An, B. Yang, Z. He, R. Lutes, A. Khan and Y. Ni, Aqueous Dispersion of Carbon Fibers and Expanded Graphite Stabilized from the Addition of Cellulose Nanocrystals to Produce Highly Conductive Cellulose Composites, ACS Sustainable Chem. Eng., 2018, 6, 3291-3298.

81 L. Shao, H. Wang, Y. Yang, Y. He, Y. Tang, H. Fang, J. Zhao, H. Xiao, K. Liang, M. Wei, W. Xu, M. Luo, Q. Wan, W. Hu, T. Gao and Z. Cui, Optoelectronic Properties of Printed Photogating Carbon Nanotube Thin Film Transistors and Their Application for Light-Stimulated Neuromorphic Devices, ACS Appl. Mater. Interfaces, 2019, 11, 12161-12169.

82 S. Kumar, M. Nehra, D. Kedia, N. Dilbaghi, K. Tankeshwar and K.-H. Kim, Carbon nanotubes: A potential material for energy conversion and storage, Prog. Energy Combust. Sci., 2018, 64, 219-253.

83 S. R. Shin, R. Farzad, A. Tamayol, V. Manoharan, P. Mostafalu, Y. S. Zhang, M. Akbari, S. M. Jung, D. Kim, M. Comotto, N. Annabi, F. E. Al-Hazmi, M. R. Dokmeci and A. Khademhosseini, A Bioactive Carbon NanotubeBased Ink for Printing 2D and 3D Flexible Electronics, Adv. Mater., 2016, 28, 3280-3289.

84 B. Wang, R. Jiang, W. Song and H. Liu, Controlling dispersion of graphene nanoplatelets in aqueous solution by ultrasonic technique, Russ. J. Phys. Chem. A, 2017, 91, 1517-1526.

$85 \mathrm{~W}$. Zhao, F. Wu, H. Wu and G. Chen, Preparation of Colloidal Dispersions of Graphene Sheets in Organic Solvents by Using Ball Milling, J. Nanomater., 2010, 2010, 1-5.

86 S. Kim, B. Tserengombo, S.-H. Choi, J. Noh, S. Huh, B. Choi, H. Chung, J. Kim and H. Jeong, Experimental investigation of dispersion characteristics and thermal conductivity of 
various surfactants on carbon based nanomaterial, Int. Commun. Heat Mass Transfer, 2018, 91, 95-102.

87 D. Song, A. Mahajan, E. B. Secor, M. C. Hersam, L. F. Francis and C. D. Frisbie, High-Resolution Transfer Printing of Graphene Lines for Fully Printed, Flexible Electronics, ACS Nano, 2017, 11, 7431-7439.

88 E. B. Secor, P. L. Prabhumirashi, K. Puntambekar, M. L. Geier and M. C. Hersam, Inkjet Printing of High Conductivity, Flexible Graphene Patterns, J. Phys. Chem. Lett., 2013, 4, 1347-1351.

89 C.-L. Lee, C.-H. Chen and C.-W. Chen, Graphene nanosheets as ink particles for inkjet printing on flexible board, Chem. Eng. J., 2013, 230, 296-302.

90 M. Michel, C. Biswas and A. B. Kaul, High-performance inkjet printed graphene resistors formed with environmentally-friendly surfactant-free inks for extreme thermal environments, Applied Materials Today, 2017, 6, 16-21.

91 A. Koutsioukis, V. Georgakilas, V. Belessi and R. Zboril, Highly Conductive Water-Based Polymer/Graphene Nanocomposites for Printed Electronics, Chemistry, 2017, 23, 8268-8274.

92 M. H. Overgaard, M. Kühnel, R. Hvidsten, S. V. Petersen, T. Vosch, K. Nørgaard and B. W. Laursen, Highly Conductive Semitransparent Graphene Circuits ScreenPrinted from Water-Based Graphene Oxide Ink, Adv. Mater. Technol., 2017, 2.

93 S. Majee, C. Liu, B. Wu, S. L. Zhang and Z. B. Zhang, Ink-jet printed highly conductive pristine graphene patterns achieved with water-based ink and aqueous doping processing, Carbon, 2017, 114, 77-83.

94 K. Parvez, Z. S. Wu, R. Li, X. Liu, R. Graf, X. Feng and K. Mullen, Exfoliation of graphite into graphene in aqueous solutions of inorganic salts, J. Am. Chem. Soc., 2014, 136, 6083-6091.

95 A. Al Shboul, C. Trudeau, S. Cloutier, M. Siaj and J. P. Claverie, Graphene dispersions in alkanes: toward fast drying conducting inks, Nanoscale, 2017, 9, 9893-9901.

96 S. Man, Graphene Based Inks for Printed Electronics, Uppsala University, SE-75121 Uppsala, Sweden, 2019.

97 Y. Meng, X.-B. Xu, H. Li, Y. Wang, E.-X. Ding, Z.-C. Zhang and H.-Z. Geng, Optimisation of carbon nanotube ink for large-area transparent conducting films fabricated by controllable rod-coating method, Carbon, 2014, 70, 103110.

98 C. Preston, D. Song, J. Dai, Z. Tsinas, J. Bavier, J. Cumings, V. Ballarotto and L. Hu, Scalable nanomanufacturing of surfactant-free carbon nanotube inks for spray coatings with high conductivity, Nano Res., 2015, 8, 2242-2250.

99 S. Wang, N. Liu, J. Tao, C. Yang, W. Liu, Y. Shi, Y. Wang, J. Su, L. Li and Y. Gao, Inkjet printing of conductive patterns and supercapacitors using a multi-walled carbon nanotube/Ag nanoparticle based ink, J. Mater. Chem. A, 2015, 3, 2407-2413.

100 S. Azoz, A. L. Exarhos, A. Marquez, L. M. Gilbertson, S. Nejati, J. J. Cha, J. B. Zimmerman, J. M. Kikkawa and L. D. Pfefferle, Highly conductive single-walled carbon nanotube thin film preparation by direct alignment on substrates from water dispersions, Langmuir, 2015, 31, 1155-1163.

101 D. Dainelli, N. Gontard, D. Spyropoulos, E. Zondervan-van den Beuken and P. Tobback, Active and intelligent food packaging: legal aspects and safety concerns, Trends Food Sci. Technol., 2008, 19, S103-S112.

102 S. Y. Tseng, S. Y. Li, S. Y. Yi, A. Y. Sun, D. Y. Gao and D. Wan, Food Quality Monitor: Paper-Based Plasmonic Sensors Prepared Through Reversal Nanoimprinting for Rapid Detection of Biogenic Amine Odorants, ACS Appl. Mater. Interfaces, 2017, 9, 17306-17316.

103 S. J. Calva-Estrada, M. Jiménez-Fernández and E. LugoCervantes, Protein-Based Films: Advances in the Development of Biomaterials Applicable to Food Packaging, Food Eng. Rev., 2019, 11, 78-92.

104 C. Moreno, M. J. Andrade-Cuvi, M. J. Zaro, M. Darre, A. R. Vicente and A. Concellón, Short UV-C Treatment Prevents Browning and Extends the Shelf-Life of FreshCut Carambola, J. Food Qual., 2017, 2017, 1-9.

105 S. Yildirim, B. Röcker, M. K. Pettersen, J. Nilsen-Nygaard, Z. Ayhan, R. Rutkaite, T. Radusin, P. Suminska, B. Marcos and V. Coma, Active Packaging Applications for Food, Compr. Rev. Food Sci. Food Saf., 2018, 17, 165-199.

106 P. Puligundla, J. Jung and S. Ko, Carbon dioxide sensors for intelligent food packaging applications, Food Control, 2012, 25, 328-333.

107 M. D. Wilson, R. A. Stanley, A. Eyles and T. Ross, Innovative processes and technologies for modified atmosphere packaging of fresh and fresh-cut fruits and vegetables, Crit. Rev. Food Sci. Nutr., 2019, 59, 411-422.

108 F. Bibi, C. Guillaume, N. Gontard and B. Sorli, Wheat gluten, a bio-polymer to monitor carbon dioxide in food packaging: electric and dielectric characterization, Sens. Actuators, B, 2017, 250, 76-84.

109 I. M. Perez de Vargas-Sansalvador, M. M. Erenas, D. Diamond, B. Quilty and L. F. Capitan-Vallvey, Water based-ionic liquid carbon dioxide sensor for applications in the food industry, Sens. Actuators, B, 2017, 253, 302-309.

$110 \mathrm{~W}$. Lang and R. Jedermann, What Can MEMS Do for Logistics of Food? Intelligent Container Technologies: A Review, IEEE Sensors Journal, 2016, 16, 6810-6818.

111 S. Santoro, A. J. Moro, C. Portugal, J. G. Crespo, J. C. Lima and I. M. Coelhoso, Monitoring oxygen permeation through polymeric packaging films using a ratiometric luminescent sensor, J. Food Eng., 2016, 189, 37-44.

112 E. L. Papadopoulou, D. Morselli, M. Prato, A. Barcellona, A. Athanassiou and I. S. Bayer, An efficient pure polyimide ammonia sensor, J. Mater. Chem. C, 2016, 4, 7790-7797.

113 C. A. Aceves Lara, V. Athès, P. Buche, G. Della Valle, V. Farines, F. Fonseca, V. Guillard, K. Kansou, M. Kristiawan, V. Monclus, J.-R. Mouret, A. Ndiaye, P. Neveu, S. Passot, C. Pénicaud, J.-M. Sablayrolles, J.-M. Salmon, R. Thomopoulos and I. C. Trelea, The virtual food system: Innovative models and experiential feedback in technologies for winemaking, the cereals 
chain, food packaging and eco-designed starter production, Innovative Food Sci. Emerging Technol., 2018, 46, 54-64.

114 C. Alamprese, C. Cappa, S. Ratti, S. Limbo, M. Signorelli, D. Fessas and M. Lucisano, Shelf life extension of wholewheat breadsticks: formulation and packaging strategies, Food Chem., 2017, 230, 532-539.

115 A. Paternoster, J. Van Camp, S. Vanlanduit, A. Weeren, J. Springael and J. Braet, The performance of beer packaging: vibration damping and thermal insulation, Food Packaging and Shelf Life, 2017, 11, 91-97.

116 O. A. Odeyemi, C. M. Burke, C. J. S. Bolch and R. Stanley, Evaluation of spoilage potential and volatile metabolites production by Shewanella baltica isolated from modified atmosphere packaged live mussels, Food Res. Int., 2018, 103, 415-425.

117 E. Poyatos-Racionero, J. V. Ros-Lis, J.-L. Vivancos and R. Martínez-Máñez, Recent advances on intelligent packaging as tools to reduce food waste, J. Cleaner Prod., 2018, 172, 3398-3409.

118 P. Kumar, S. K. Mohanty, S. Guruswamy, Y. R. Smith and M. Misra, Detection of Food Decay Products Using Functionalized One-Dimensional Titania Nanotubular Arrays, IEEE Sensors Letters, 2017, 1, 1-4.

119 C. Schaude, C. Meindl, E. Frohlich, J. Attard and G. J. Mohr, Developing a sensor layer for the optical detection of amines during food spoilage, Talanta, 2017, 170, 481-487.

120 A. T. Alreshaid, J. G. Hester, W. Su, Y. Fang and M. M. Tentzeris, Review-Ink-Jet Printed Wireless Liquid and Gas Sensors for IoT, SmartAg and Smart City Applications, J. Electrochem. Soc., 2018, 165, B407-B413.

121 S. Matindoust, A. Farzi, M. Baghaei Nejad, M. H. Shahrokh Abadi, Z. Zou and L.-R. Zheng, Ammonia gas sensor based on flexible polyaniline films for rapid detection of spoilage in protein-rich foods, J. Mater. Sci.: Mater. Electron., 2017, 28, 7760-7768.

122 E. Omanovic-Miklicanin and S. Valzacchi, Development of new chemiluminescence biosensors for determination of biogenic amines in meat, Food Chem., 2017, 235, 98-103.
123 O. Gubanova, M. Andrianova, M. Saveliev, N. Komarova, E. Kuznetsov and A. Kuznetsov, Fabrication and package of ISFET biosensor for micro volume analysis with the use of direct ink writing approach, Mater. Sci. Semicond. Process., 2017, 60, 71-78.

124 F. Magesa, Y. Wu, Y. Tian, J.-M. Vianney, J. Buza, Q. He and Y. Tan, Graphene and graphene like 2D graphitic carbon nitride: electrochemical detection of food colorants and toxic substances in environment, Trends Environ. Anal. Chem., 2019, 23.

125 W. Dudefoi, A. Villares, S. Peyron, C. Moreau, M.-H. Ropers, N. Gontard and B. Cathala, Nanoscience and nanotechnologies for biobased materials, packaging and food applications: new opportunities and concerns, Innovative Food Sci. Emerging Technol., 2018, 46, 107-121.

126 N. Yang, X. Chen, T. Ren, P. Zhang and D. Yang, Carbon nanotube based biosensors, Sens. Actuators, B, 2015, 207, 690-715.

127 S. Tarish, Y. Xu, Z. Wang, F. Mate, A. Al-Haddad, W. Wang and Y. Lei, Highly efficient biosensors by using wellordered $\mathrm{ZnO} / \mathrm{ZnS}$ core/shell nanotube arrays, Nanotechnology, 2017, 28, 405501.

128 F. Bibi, C. Guillaume, N. Gontard and B. Sorli, A review: RFID technology having sensing aptitudes for food industry and their contribution to tracking and monitoring of food products, Trends Food Sci. Technol., 2017, 62, 91-103.

129 G. S. Lorite, T. Selkala, T. Sipola, J. Palenzuela, E. Jubete, A. Vinuales, G. Cabanero, H. J. Grande, J. Tuominen, S. Uusitalo, L. Hakalahti, K. Kordas and G. Toth, Novel, smart and RFID assisted critical temperature indicator for supply chain monitoring, J. Food Eng., 2017, 193, 20-28.

130 M. Creydt and M. Fischer, Blockchain and more - Algorithm driven food traceability, Food Control, 2019, 105, 45-51.

131 M. Borgese and F. Costa, An Inkjet Printed Chipless RFID Sensor for Wireless Humidity Monitoring, IEEE Sensors Journal, 2017, 17, 5. 